\title{
Pheromone transduction in moths
}

\author{
Monika Stengl* \\ FB 10, Biology, Animal Physiology, University of Kassel, Kassel, Germany
}

\section{Edited by:}

Dieter Wicher, Max Planck Institute for

Chemical Ecology, Germany

\section{Reviewed by:}

Bernd Grunewald, Johann Wolfgang

Goethe University, Germany

Dean P. Smith, University of Texas

Southwestern Medical Center at

Dallas, USA

\section{*Correspondence:}

Monika Stengl, FB 10, Biology, Animal Physiology, University of Kassel, Heinrich-Plett-Str. 40, 34132 Kassel,

Germany.

e-mail: stengl@uni-kassel.de
Calling female moths attract their mates late at night with intermittent release of a species-specific sex-pheromone blend. Mean frequency of pheromone filaments encodes distance to the calling female. In their zig-zagging upwind search male moths encounter turbulent pheromone blend filaments at highly variable concentrations and frequencies. The male moth antennae are delicately designed to detect and distinguish even traces of these sex pheromones amongst the abundance of other odors. Its olfactory receptor neurons sense even single pheromone molecules and track intermittent pheromone filaments of highly variable frequencies up to about $30 \mathrm{~Hz}$ over a wide concentration range. In the hawkmoth Manduca sexta brief, weak pheromone stimuli as encountered during flight are detected via a metabotropic PLC $\beta$-dependent signal transduction cascade which leads to transient changes in intracellular $\mathrm{Ca}^{2+}$ concentrations. Strong or long pheromone stimuli, which are possibly perceived in direct contact with the female, activate receptor-guanylyl cyclases causing long-term adaptation. In addition, depending on endogenous rhythms of the moth's physiological state, hormones such as the stress hormone octopamine modulate second messenger levels in sensory neurons. High octopamine levels during the activity phase maximize temporal resolution cAMP-dependently as a prerequisite to mate location. Thus, I suggest that sliding adjustment of odor response threshold and kinetics is based upon relative concentration ratios of intracellular $\mathrm{Ca}^{2+}$ and cyclic nucleotide levels which gate different ion channels synergistically. In addition, I propose a new hypothesis for the cyclic nucleotide-dependent ion channel formed by insect olfactory receptor/coreceptor complexes. Instead of being employed for an ionotropic mechanism of odor detection it is proposed to control subthreshold membrane potential oscillation of sensory neurons, as a basis for temporal encoding of odors.

Keywords: insect olfaction, second messengers, octopamine, circadian rhythms, signal transduction cascades, field potentials, subthreshold membrane potential oscillations, temporal encoding

\section{MALE MOTHS DETECT PHEROMONES WITH ASTOUNDING SENSITIVITY AND HIGH TEMPORAL RESOLUTION, BUT UNDERLYING TRANSDUCTION CASCADES ARE NOT UNDERSTOOD}

Sensitive odor detection is a prerequisite to survival and reproduction in many insect species, especially in short-lived moths. While they rest during the day late at night female moths release pulses of a sex-pheromone blend to attract their mates (Itagaki and Conner, 1988). Pheromones are species-specific odors with properties of hormones. They signal the physiological state of the individual insect to their conspecifics. Air turbulences tear and whirl the pheromone blend pulse pattern into intermittent odor filaments of varying blend concentrations and frequencies. Timedependently in synchrony with the female, male moths detect the pheromone filaments at astounding sensitivity with specialized hair-like sensilla on their antennae (Kaissling and Priesner, 1970; Sanes and Hildebrand, 1976; Almaas et al., 1991; reviews: Kaissling and Thorson, 1980; Kaissling, 1987). With forward pointed antennae male moths fly upwind, brushing the air with long trichoid sensilla. They adsorb about $30 \%$ of the lipophilic pheromones in a surrounding air stream on the waxy surface of the antennal cuticle (Kaissling, 1987). Hawkmoths fly with a velocity of about $3.5 \mathrm{~m} / \mathrm{s}$ and beat their wings at a high frequency of about $30 \mathrm{~Hz}$. Flight velocity and wing beat frequency affect sampling of odorants. It is assumed that each downstroke of the wing accelerates airflow over the olfactory sensilla and, thus, periodically allows for odor sampling, about every $30 \mathrm{~ms}$ (Tripathy et al., 2010).

Next to the species-specific pheromone blend composition, this intermittency of the pheromone signal is a critical prerequisite for eliciting arousal in the male moth, for starting and maintaining the male's characteristic zig-zagging anemotaxis (Kennedy et al., 1981; Murlis and Jones, 1981; Baker et al., 1985; Baker and Haynes, 1989; Tumlinson et al., 1989; Vickers and Baker, 1992; Vickers, 2000; Koehl, 2006; Lei et al., 2009). Constant or very strong pheromone stimulation results in cessation of the males search, possibly caused by adaptation of the sensory cells (Baker et al., 1988). Owing to the turbulent air, distance to the female is encoded in the mean frequency of pheromone filaments rather than in a concentration gradient. From behavioral experiments it was calculated that male moths can assess pheromone blend ratios within less than $100 \mathrm{~ms}$, possibly comparing two consecutive antennal "sniffs" (review: De Bruyne and Baker, 2008). Upon loss of pheromone during zigzag upwind flight they respond with cross wind-casting within 300-500 ms (Baker and Vogt, 1988). Apparently, sensitized silkmoth antennal olfactory receptor neurons (ORNs) can detect single pheromone molecules and hawkmoth ORNs differentiate pheromone 
concentrations over at least 4 log units (Kaissling and Priesner, 1970; Kaissling, 1987; Dolzer et al., 2003). In addition, the olfactory system appears to follow intermittent odor signals of about $30 \mathrm{~Hz}$ (Justus et al., 2005; Ito et al., 2008; Tripathy et al., 2010). Therefore, evolution shaped the olfactory system to be as sensitive as possible and to allow reaction times within the range of $30 \mathrm{~ms}$.

Still it is not resolved which olfactory signal transduction cascades are responsible for the astounding sensitivity and for the fast temporal resolution of pheromone blend detection and discrimination. There is strong controversy in the field of olfaction in the interpretation of apparently conflicting genetic and physiological data. Especially the characterization of receptor-ion channel complexes raised the hypothesis that insects smell via speedy ionotropic signal transduction in contrast to vertebrates which employ sensitive G-protein coupled, metabotropic odor transduction cascades. This review focuses on sex-pheromone-detection in the hawkmoth Manduca sexta due to an available primary cell culture system which greatly facilitated physiological studies (Stengl and Hildebrand, 1990), while only briefly brushing over perireceptor events which were reviewed recently (Kaissling, 2009). In this review I suggest novel explanations for the surprising variety of different signal transduction cascades reported in moth pheromone transduction which differ greatly from a previously suggested quantitative model of insect transduction (Gu et al., 2009). I propose a new testable hypothesis of receptor-ion channel complex-function in the control of subthreshold membrane potential oscillations and, thus, in the control of temporal encoding in moth pheromone transduction.

\section{FUNCTIONAL ANATOMY OF PHEROMONE-SENSITIVE ANTENNAL SENSILLA}

Insects detect odorants mostly with their antennae (von Frisch, 1921). In moths the sexually dimorphic antennal flagellum of the male is enlarged to house extra arrays of pheromone-specific long trichoid sensilla. In addition, it contains cholinergic, shorter sensilla basiconica which detect general odorants and sensilla of other modalities (Altner and Prillinger, 1980; Keil and Steinbrecht, 1984; Lee and Strausfeld, 1990; Stengl et al., 1990).The extreme sensitivity of moth pheromone detection observed is obtained by a number of different mechanisms, including the specific morphology of the moth's antennal sensilla. The pheromone-sensitive trichoid sensilla (Figure 1) are the longest and most abundant (38\% of 2100 sensilla per annulus in M. sexta) cuticular hairs which form regular brush-like arrays on each annulus of the antennal flagellum (Keil, 1989; Lee and Strausfeld, 1990). About $32 \%$ of $3.6 \times 10^{5}$ sensory neurons of the hawkmoth antenna are pheromone-sensitive ORNs which innervate long trichoid sensilla. In $M$. sexta antennae two ORNs innervate each trichoid sensillum. One of them (Dolzer et al., 2003 ) responds to (E,Z)-10,12-hexadecadienal (=bombykal), the main sex pheromone component which makes up 31\% of the sexpheromone blend. The other of the two ORNs responds to other components of the pheromone blend such as to (E,E,Z)-10,12,14hexadecatrienal (14.7\%; Kaissling et al., 1989). Next to the ORNs each sensillum trichodeum contains about three non-neuronal cells: the trichogen, the tormogen, and the thecogen cells (Figure 1). All cells of an olfactory sensillum are born from ganglion mother cells in the antennal epithelium (Keil, 1999). During development

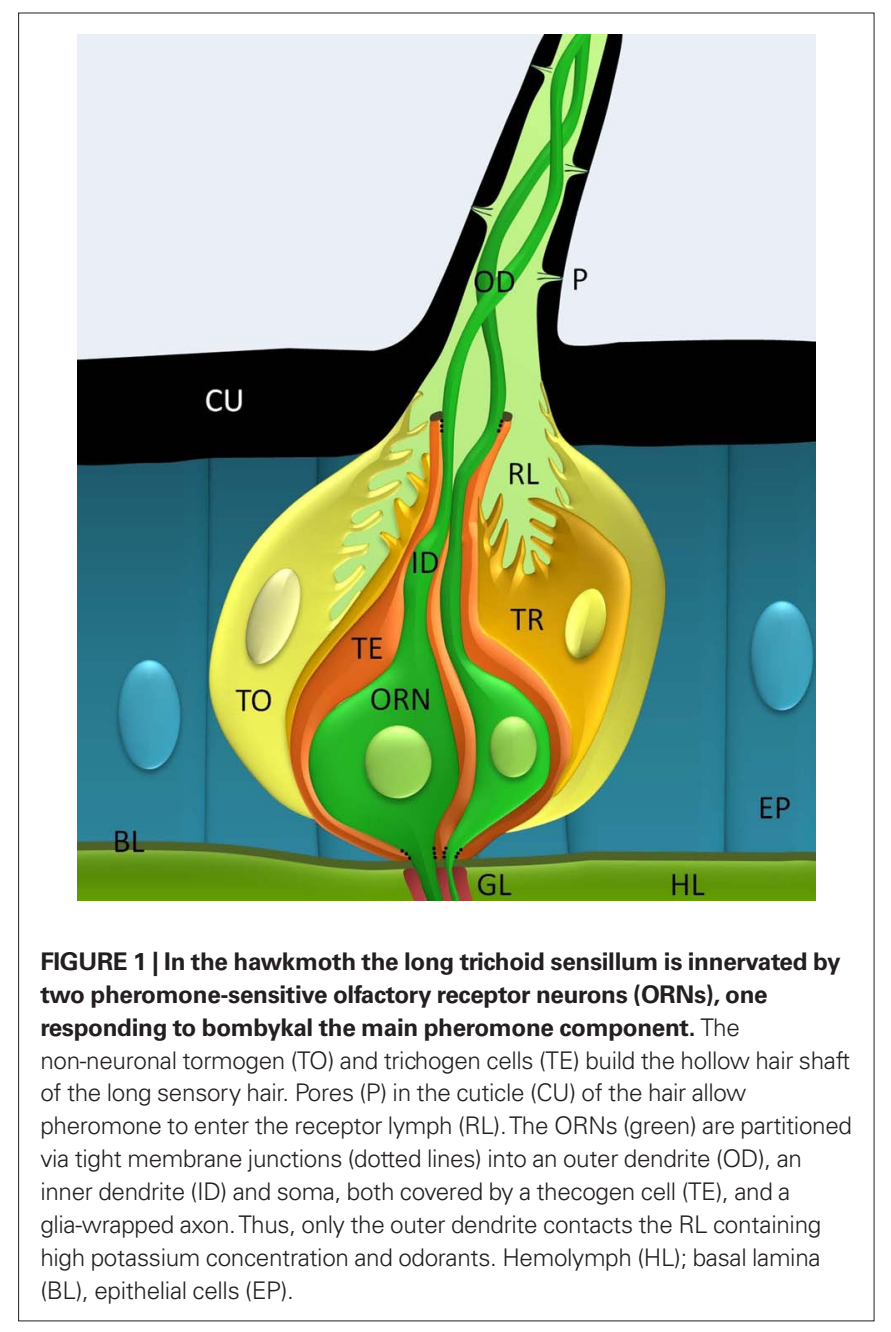

the trichogen and tormogen cells generate the hollow cuticular hair shaft with the inner sensillar lymph cavity. The dendrites of the ORNs are partitioned into an outer and inner dendrite by a short ciliary structure. The thecogen cell wraps around the inner dendrite and soma of the sensory neurons. Only the naked outer dendrites of the two bipolar ORNs extend into the sensillum lymph cavity. The outer dendrite is a modified cilium which lacks the central microtubule pair and does not contain an endoplasmic reticulum or any other organelles. It is motile and can perform oscillatory elongations and constrictions (Keil, 1993). The sensory neuron's axon, which is covered by a glial sheet, projects to the antennal lobe of the brain (Figure 1). The somata of moth ORNs are embedded between epithelial cells underneath the cuticular hair. Thus, each moth ORN is partitioned into three separate compartments: (1) the outer dendrite, (2) the inner dendrite with soma, and (3) the axon. The different compartments are isolated from each other. Very likely they maintain different external ionic milieus and different membrane compositions. The sensillum lymph contains a very high potassium concentration of about $200 \mathrm{mM}$ (reviews: Kaissling and Thorson, 1980; Thurm and Küppers, 1980; Kaissling, 2009). This intracellular-like potassium concentration is generated by vacuolartype $\mathrm{H}^{+}$-ATPases in the copious membrane folds of the tormogen and trichogen cells walling the sensillum lymph cavity. Thus, a 
transepithelial potential (TEP) of up to $40 \mathrm{mV}$ between sensillum lymph and hemolymph adds to the negative resting potential of the ORNs and increases the electrical driving force for the receptor current. This TEP shows oscillations which are affected by biogenic amines circulating in the hemolymph (Dolzer et al., 2001). Little is known about ion channels in the supporting cells. But it is clear that also the non-neuronal cells contribute to odor-dependent sensillum potentials since no direct correlation between odor-dependent sensillum potential changes and action potential responses of the sensory neurons are found (Dolzer et al., 2003).

In conclusion: The lipophilic cuticle and surface maximization of many long trichoid sensilla assure accumulation of airborne pheromones at high efficiency to improve sensitivity. It remains to be studied whether slow oscillatory elongations of the dendrite and slow TEP-oscillations are phase-locked to the moth's fast wing beat frequency and whether oscillatory wing beats ensure oscillatory odor stimulation. Furthermore, it remains to be examined whether oscillatory odor stimulation results in synchronization of ORNs to improve frequency resolution and blend assessment via mechanisms of temporal encoding. Compartmentalization of the ORN implicates differential distribution of membrane proteins and extracellular milieus which also need to be evaluated further. Finally, the nitty-gritty of nonneuronal supporting cells should not be neglected because they considerably contribute to olfactory transduction not only via generation of a modifiable TEP.

\section{PERIRECEPTOR EVENTS: FROM STIMULUS ENTRY TO PASSAGE TO OLFACTORY RECEPTOR MOLECULES}

Through pores and lipophilic pore tubules which extend into the cavity of the sensory hairs the hydrophobic pheromones enter the hair shaft and face the aqueous sensillum lymph with high protein concentrations (Keil and Steinbrecht, 1984). Supporting cells secrete these millimolar concentrations of pheromone-binding proteins (PBPs; odorant-binding proteins = OBPs in sensilla basiconica) into the sensillum lymph of trichoid sensilla (Forstner et al., 2006, 2009; Pelosi et al., 2006). The moth PBPs bind specific pheromone components with high affinity and thereby contribute to the specificity and sensitivity of the pheromone responses (Stengl et al., 1992; Steinbrecht et al., 1995; Ziegelberger, 1995; Mohl et al., 2002; Pophof, 2004; Leal et al., 2005; Grosse-Wilde et al., 2006, 2007; Kaissling, 2009). Their various functions are not yet completely resolved but the PBPs appear to act as scavenger of unspecific odorants and as carrier of specific pheromone compounds to their dendritic receptor molecule complexes. Apparently, PBPs undergo a conformational shift after pheromone binding (Ziegelberger, 1995). Then, they are enabled to transiently interact with dendritic pheromone receptor molecule-complexes (containing various molecules, see below) which allows for another conformational change which initiates pheromone degradation via enzymes (Vogt and Riddiford, 1981, 1986; Ziegelberger, 1995). Thus, moth PBPs/OBPs appear to be selectivity filters, as well as temporal filters, contributing to the specific, transient, and single interaction with dendritic olfactory receptor molecule-complexes before the odor molecules are inactivated. Studies with loss of function and gain of function mutants of the OBP LUSH in D. melanogaster generally support this notion (Laughlin et al., 2008). In addition to affecting odor detection, lush loss of function mutants decrease spontaneous activity of the ORNs (Xu et al., 2005). It is assumed that LUSH is absolutely required for the detection of the fruitfly's aggregation pheromone 11-cis vaccenyl acetate (Xu et al., 2005). Alternatively, it is possible that LUSH lowers the detection threshold of odors and prevents adaptation of receptors because it allows for only very transient binding of the odor to the receptor. Without LUSH an odorant might not be transiently bound and quickly removed from the odor receptor complex which then desensitizes. This assumption was supported by respective observations in the hawkmoth (Stengl et al., 1992). Still, the different functions of the PBPs/OBPs are under debate and remain to be investigated further. Modeling studies by Kaissling (2009) predicted that $17 \%$ of the total pheromone concentration is enzymatically degraded and $83 \%$ is bound to the PBPs within $3 \mathrm{~ms}$ after entering the sensillum lymph. In his kinetic model the half-life of the activated dendritic receptor-pheromone-PBP complex was calculated to be $0.8 \mathrm{~s}$, the EC50 was $6.8 \mu \mathrm{M}$.

In conclusion: Moth ORNs are flux detectors because antennal odor adsorption depends not only on the external odor concentration but also on the relative velocity of the air stream, the speed, and the wing beat frequency of the flying insect (Kaissling, 2009). Therefore, the latency and kinetics of the odor-dependent potential responses are also governed by the kinetics of odor entry, odor$\mathrm{PBP}(\mathrm{OBP})$-odor receptor complex interactions, and odor inactivation/enzymatic degradation. Further quantitative studies need to resolve the dynamical impact of perireceptor events in odor detection within more detail.

\section{OLFACTORY RECEPTOR MOLECULE COMPLEXES IN OUTER DENDRITES OF MOTH ORNs}

After reaching the outer dendritic membrane of ORNs pheromonePBP complexes specifically interact with olfactory receptor molecule (OR)-complexes, initiating signal transduction cascades. There are different classes of chemosensory receptor molecules described, next to other specific sensory neuron membrane proteins (SNMPs).

\section{INSECT ORs ARE UNRELATED IN SEQUENCE TO VERTEBRATE ORS}

Insect ORs appear to be largely insect-specific proteins which do not share sequence similarity to vertebrate ORs or other G-protein coupled receptors. Nevertheless, also insect ORs have predicted seven transmembrane domains, but they appear to adopt a different topology in contrast to vertebrate ORs (review: Nakagawa and Vosshall, 2009; Silbering and Benton, 2010). Studies in molecular genetics combined with immunocytochemistry revealed that dendrites of a single silkmoth ORN contain at least two different olfactory receptor molecules (ORs), apparently forming complexes at unknown density with unresolved stoichiometry (Krieger et al., 2002, 2004, 2005, 2009; Sakurai et al., 2004; Grosse-Wilde et al., 2007; Brigaud et al., 2009; review: Nakagawa and Vosshall, 2009). One of them is a widely conserved coreceptor (COR) termed OR83b in the fruitfly and MsextaOR2 in the hawkmoth (Krieger et al., 2003; Malpel et al., 2008; M. sexta: Patch et al., 2009; review: Nakagawa and Vosshall, 2009). In D. melanogaster this COR is a chaperon that is obligatory for directing ORs into dendritic membranes and thus, its destruction deletes odor responses in the fruitfly (Larsson et al., 2004; Benton et al., 2006). In moths in situ hybridizations suggested 
that MsextaOR2 is also located to pheromone-sensitive long trichoid sensilla and, thus, appears to play a role in pheromone transduction (Patch et al., 2009). This hypothesis is confirmed by Nakagawa et al. (2005) who found the COR colocalized with pheromone receptors in Bombyx mori. However, relative levels of MsextaOR2 expression are much higher in the female antenna than in the male antenna. This result suggests that the COR is either not expressed in all pheromone-sensitive trichoid sensilla of male hawkmoths or that it is expressed at considerably lower level in the pheromone system as compared to the general odor detecting system (Patch et al., 2009). Due to these conflicting results it is necessary to perform more studies in different insect species to resolve whether pheromone transduction indeed depends on an OR/COR complex.

\section{THE SENSORY NEURON MEMBRANE PROTEINS IN DENDRITIC MEMBRANES OF ORNs}

The SNMPs were identified in the dendritic membrane of male and female moth ORNs and supporting cells (Rogers et al., 1997, 2001a,b; Forstner et al., 2008). The SNMPs are related to the CD36 receptor family of glycoproteins, which recognize long-chain fatty acids, oxidized phospholipids, and lipoproteins (review: Silverstein and Febbraio, 2009). Their functions in olfaction are not yet resolved but it is hypothesized that SNMPs might be additional coreceptors which are involved in the transfer of lipophilic pheromones or pheromone-PBP-complexes to ORs (Rogers et al., 2001b; Vogt et al., 2009). This assumption is supported by studies in D. melanogaster which demonstrated that a SNMP is required for pheromone responses (Benton et al., 2007). Because SNMP mutants showed increased spontaneous activity it was suggested that SNMP inhibits the receptor in absence of pheromone (Benton et al., 2007; Jin et al., 2008). However, the additional expression of SNMPs in non-neuronal supporting cells of trichoid sensilla suggests additional functions (Forstner et al., 2008). Because supporting cells show pheromone-induced cGMP elevations and NADPH-diaphorase activity (which is indicative of nitric oxide synthase) only after very strong, long pheromone stimuli, it remains to be examined whether SNMPs might be pheromone-sensitive coreceptors of receptor guanylyl cyclases (GCs) in supporting cells (Stengl and Zintl, 1996; Stengl et al., 2001).

\section{OTHER RECEPTORS FOUND IN DENDRITES OF ORNs}

Next to the ORs and to gustatory receptors, a third family of chemosensory receptors was identified in the fruitfly; the ionotropic receptors (IRs). The IRs share homology to a class of ligand-gated ion channels (Benton, 2009). Their functions in the antenna still need to be resolved. Whether the IRs are present also in the moth antenna is unknown. In addition, different types of receptor GCs and of octopamine receptors were located in moth antennae (Von Nickisch-Rosenegk et al., 1996; Simpson et al., 1999; Nighorn et al., 2001; Morton and Nighorn, 2003; Dacks et al., 2006). Whether $\mathrm{CO}_{2}^{-}$, or oxygen-receptors as described in fruitflies are also present in moth pheromone-sensitive ORNs remains to be examined (Benton, 2009).

In conclusion: The outer dendrites of pheromone-specific moth ORNs comprise apparently heteromeric OR/COR complexes. These complexes appear also to be associated with SNMPs, which might aggregate PBPs loaded with pheromone. Furthermore, octopaminereceptors and receptor-type-, but not soluble GCs are present in the dendrites of moth ORNs. The functional implications of these large receptor complexes in temporal encoding of odor transduction are discussed below.

\section{SUBTHRESHOLD MEMBRANE POTENTIAL OSCILLATIONS OF ORNs AND TEMPORAL ENCODING OF ODORS}

First odors bind to their specific receptors (ORs), then, conformational changes of ORs initiate signal transduction cascades which transduce the chemical signal to a graded potential change (receptor potential) in the sensory neuron. If this receptor potential reaches a threshold of about $-40 \mathrm{mV}$ at the axon hillock it elicits opening of voltage-dependent $\mathrm{Na}^{+}$and $\mathrm{K}^{+}$channels, and thus action potentials (=spikes). To understand odor transduction cascades in insects it is important to determine which schemes of information encoding they employ. Thus, before conflicting hypotheses of odor transduction cascades are being discussed, first, I briefly compare "rate codes" and "temporal encoding" in chemosensory neurons. Then, I will summarize evidence for the type of coding employed by insect odor transduction cascades.

"Rate codes" imply that increasing odor concentrations result in increasing action potential frequencies in ORNs. Dose-response curves of ORNs are semi-logarithmic with a linear increase of the response with $10 \times$ rising odor concentration (bombykal cell in M. sexta: Dolzer et al., 2003). Thus, odor concentration is encoded in the action potential rate of a single ORN. In the hawkmoth the first five interspike intervals, but not the average action potential frequency over the pheromone stimulus duration encode pheromone quantity over at least 4 log units (Dolzer et al., 2003).

Next to the "rate code," olfactory information can also be encoded in the time domain, called "temporal encoding" (Milner, 1974; Singer and Gray, 1995; Knüsel et al., 2007; Ito et al., 2008, 2009). In temporal encoding one assumes that more important than the frequency of action potentials elicited in single cells is at what time the action potentials occur in a population of cells which respond to the same input. Thus, the information is encoded, e.g., in the latency of the first odor-dependent action potential elicited at the level of a neuronal population. The latency may be calculated with respect to a local field potential oscillation, generated via synchronized subthreshold membrane potential oscillations in the respective neurons. On the population level it is assumed that all cells which process the same stimulus express synchronized first action potentials with zero phase difference or constant phase relationship (Nadasdy, 2010). The phase implies the time when the action potential occurs. To obtain synchronization of spikes within the range of ms amongst a population of neurons different mechanisms of coupling (=synchronization) can be employed. Most commonly self-organized coupling is obtained with interacting neuronal oscillators. A neuronal oscillator generates endogenous subthreshold membrane potential oscillations which underlie spontaneous spike activity. Subthreshold membrane potential oscillations provide a temporal preference for input detection. Stimulus-induced receptor potentials as well as neurotransmitter-induced postsynaptic potentials will reach action potential threshold earlier, if they superimpose at the depolarizing phase of endogenous subthreshold membrane potential oscillations, rather than at the hyperpolarizing phase. As soon as any two oscillators have similar periods (interspike intervals) any type of 
interaction will synchronize both oscillators causing a stable phase relationship and a common period. For example in the cockroach brain gap junctions maintain synchronized periods of neuronal oscillators at a stable phase difference (Schneider and Stengl, 2005, 2006, 2007). If these coupled oscillators are transiently inhibited at the same time via an inhibitory interneuron zero phase difference results. Thus, a transient neuronal ensemble is generated which contains synchronized neurons which all fire their action potentials at the same time or at integer multiples of the same time. This means, depending on the input (the odor applied) transient neuronal ensembles can be obtained which are recruited into variable functions from the same population of coupled neurons. Thus, an "across fiber pattern" of ORNs could mean that not a single neuron encodes a specific odor quality and quantity, but rather a specific neuron can encode sequentially different odor qualities/quantities depending on the ensemble it is recruited to (Johnson et al., 1991; Ito et al., 2009; Raman et al., 2010).

In the olfactory system of vertebrates Junek et al. (2010) demonstrated that temporal encoding is prevalent over rate codes. They found that latency rank patterns of odor responses specifically encode odor quality and quantity, more reliably than action potential firing rates. They proved that the latency of the first action potential of an odor response is most instrumental for odor encoding already at the periphery. In addition, the importance of latency rank patterns suggested that the phase relationships of the first odor-dependent action potential elicited amongst different ORNs is important and needs to be tightly controlled, possibly via different mechanisms which couple ORNs. That also in the olfactory system of insects temporal encoding is important was shown mostly in recordings of the olfactory pathway in the brain (review: Laurent, 2002) and more recently also for ORNs (Ito et al., 2009; Raman et al., 2010). Also in ORNs of M. sexta and B. mori the latency of the first action potential elicited decreases with increasing odor concentration (Kaissling and Priesner, 1970). However, in moths it has not been thoroughly examined yet over which concentration range latencies encode odor concentration on the level of a single ORN or on the population level. But because insect ORNs, as well as vertebrate ORNs are spontaneously active and generate bursts of action potentials they very likely employ temporal encoding strategies (Gesteland, 1971; Kaissling, 1987; De Bruyne et al., 2001; Dolzer et al., 2001; Duchamp-Viret et al., 2005). The interspike intervals of spontaneous activity in ORNs of $M$. sexta are not randomly distributed and phases of action potentials are advanced via current injection (Dolzer et al., 2001; Nadasdy, 2010). This hints that the ORNs resting potential produces subthreshold membrane potential oscillations with different superimposed ultradian frequencies: one controls the frequency of bursts, one interspike intervals within bursts, and another interspike intervals between bursts. These ultradian membrane potential oscillations appear to be endogenous since regularly oscillating membrane potentials were recorded intracellularly in isolated ORNs from $M$. sexta in vitro, in addition to very regularly oscillating $\mathrm{Ca}^{2+}$ currents in the same frequency range which were observed in patch clamp recordings (Stengl, 1990). Comparably to cockroach circadian pacemaker cells (Schneider and Stengl, 2005, 2007), next to ultradian oscillations ORNs also show daytimedependent changes in the spontaneous activity with the highest frequency during the moth's activity phase (Flecke and Stengl, 2009).
Since moth ORNs express circadian rhythms and circadian clock genes, as do fruitfly and cockroach ORNs, it is likely that also moth ORNs are endogenous circadian oscillators (Krishnan et al., 1999, 2008; Tanoue et al., 2004, 2008; Merlin et al., 2006, 2007; Schuckel et al., 2007; Saifullah and Page, 2009). In moths it is not known whether $I_{\mathrm{h}}$ currents (Krannich, 2008) or other ion channels provide the pacemaking inward currents at hyperpolarizing potentials, underlying these different, superimposed, spontaneous oscillations of the resting potential.

Not only in D. melanogaster heteromeric OR/COR complexes mediate spontaneous activity because they form constitutively open non-specific cation channels even at negative resting potentials which leak depolarizing $\mathrm{Ca}^{2+}$ currents into ORNs (Sato et al., 2008; Wicher et al., 2008). Rising intracellular $\mathrm{Ca}^{2+}$ concentrations and increasing depolarization then might open voltage- and $\mathrm{Ca}^{2+}$ dependent cation and $\mathrm{Cl}^{-}$channels found in ORNs (Zufall et al., 1991a; Dolzer et al., 2008; Pézier et al., 2010). Possibly, these ion channel openings might underlie the elementary receptor potentials (bumps) observed in moth ORNs (Minor and Kaissling, 2003). The $\mathrm{Ca}^{2+}$-dependent de- or hyperpolarizing ion channels cause ultradian oscillations of the membrane potential. Since the OR-COR ion channel complexes appear to be gated via cAMP (Wicher et al., 2008) they could be modulated via adenylyl cyclaseactivating hormones such as octopamine (Figure 2). Furthermore, in D. melanogaster the availability of OR complexes in dendrites is controlled via an endogenous circadian clock (Tanoue et al., 2008). Therefore, experimental evidence is provided that OR-COR complexes are a prerequisite to metabotropically modifiable subthreshold membrane potential oscillations with superimposed ultradian and circadian periods in fruitflies.

According to theories of temporal encoding (Nadasdy, 2010) it is likely that ultradian subthreshold membrane potential oscillations in insect ORNs are an obligatory prerequisite to the phase control of the first action potential elicited in odor responses and are used for temporal encoding of odor blend quality and quantity. In addition, regularly patterned odor stimuli as might be generated by the beating wings of the flying moth will entrain ultradian membrane potential oscillations of ORNs to resonate in synchrony, thus providing phase-coupling on the population level of ORNs. Stimulus-dependent synchronization significantly increases the temporal resolution of the insect olfactory system and its fidelity in fast odor blend assessment (Tripathy et al., 2010). In addition, synchronization of many sensory neurons would decrease odor detection threshold, because more antennal cells could be recruited into an ensemble by the same stimulus, providing synchronized summed input into postsynaptic antennal lobe neurons (Ito et al., 2009; Raman et al., 2010).

In conclusion: Hallmarks of temporal encoding are endogenous subthreshold membrane potential oscillations generating spontaneously active neurons as well as different means of synchronization to recruit neuronal ensembles into a specific function. Also insect ORNs are endogenous oscillators which express ultradian and circadian subthreshold membrane potential oscillations which result in a temporal preference for odor detection. I propose that the leaky, metabotropically modifiable OR-COR ion channel complex is instrumental for these important properties which could underlie temporal encoding of odors also in insects (Figure 2). 


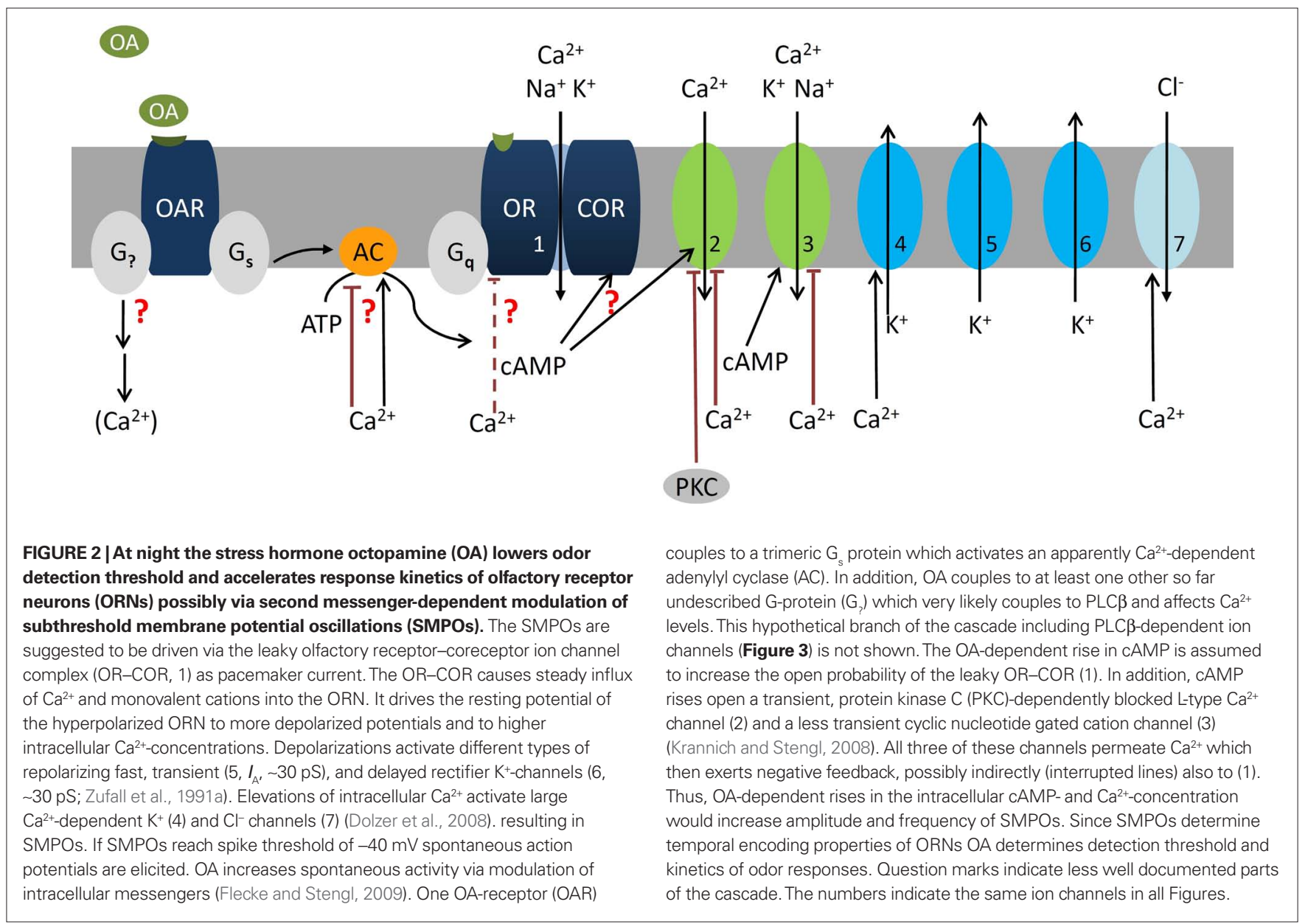

\section{OLFACTORY SIGNAL TRANSDUCTION CASCADES}

In insects odor-dependent signal transduction cascades that transduce the odor stimulus into a graded receptor potential and action potential responses are still under lively debate. Based on genetic and physiological analysis of D. melanogaster, B. mori, and mosquito ORs expressed in vertebrate cell lines Sato et al. (2008) claimed that the main mechanism of insect odor and pheromone transduction is a rapid ionotropic pathway employing the OR/COR complex as odor-gated ion channel without involvement of any G-proteincoupled metabotropic cascades which would amplify the signal. In contrast to this hypothesis several different metabotropic cascades were reported to affect odor and pheromone transduction in different insect species. Here, I will summarize experimental evidences in support of either hypothesis. Then, I will interpret the apparently conflicting results for each cascade and will put forward my own hypothesis of pheromone transduction in moths (Figures 2-5).

\section{HETEROLOGOUS OR/COR COMPLEX-DEPENDENT SIGNAL TRANSDUCTION CASCADES}

Studies suggested that $D$. melanogaster ORs signal independently of heterotrimeric G-proteins (Sato et al., 2008; Smart et al., 2008). Based on previous evidence it was proposed that a directly odorgated fast ionotropic mechanism via OR/OR83b-formed ion channels is the main odor-dependent transduction pathway eliciting receptor potentials (Nakagawa et al., 2005; Sato et al., 2008). This was claimed not only for general odorants in the fruitfly but also for pheromone-transduction in moths. This hypothesis is based upon the observation that insect ORs are seven-transmembrane receptors which are inversely inserted into the dendritic membrane with the $\mathrm{N}$-terminal reaching into the inside of the cell (Benton et al., 2006; Lundin et al., 2007). Thus, the known G-protein binding motif on the C-terminal is located at the extracellular site and cannot account for a metabotropic cascade. In addition, odor-dependent but GTP-/ATP-independent inward currents were recorded after expression of fruitfly, silkmoth, and mosquito ORs coexpressed with the respective OR83b (COR)/-homologs in HeLa and HEK293 cells (Sato et al., 2008; Wicher et al., 2008). However, unphysiologically strong and long pheromone stimuli of $10 \mu \mathrm{M}$ bombykol for several seconds which do not occur in natural surroundings of the moths were necessary to elicit a fast, small ionotropic current via bombykol-receptor-COR complexes (Sato et al., 2008). In comparison, dependent on the expression of OR22a/OR83b, $100 \mathrm{nM}$ ethyl butyrate pulses of $1 \mathrm{~s}$ duration elicited an ionotropic current which peaked at $1 \mathrm{~s}$ and terminated after $10 \mathrm{~s}$. It was followed by a stronger metabotropic current component which developed after about $10 \mathrm{~s}$, peaked at about $60 \mathrm{~s}$, and terminated after about 80 s (Wicher et al., 2008). The less sensitive ionotropic current component appeared to be a current via the OR/OR83b-formed 
ion channels, gated via binding of odor to the OR-subunit. This ionotropic current did not depend on the presence of ATP or GTP, in contrast to the slower and more sensitive metabotropic current component. The metabotropic current appeared to be mediated via binding of cyclic nucleotides to the OR-COR-formed ion channel, which apparently increased its probability to open. Whether G-protein-dependent activation of an adenylyl cyclase was mediated via OR homodimers with C-termini intracellularly or via a new G-protein-binding domain at the intracellular N-terminus, or via another $G_{s}$-coupled receptor remains to be examined more thoroughly. The time courses of both of these current components, the ionotropic as well as the cGMP/cAMP-dependent metabotropic currents do not match the time course of non-adapted phasic odor responses in intact ORNs or of odor sampling of moths, which both last less than $100 \mathrm{~ms}$ (Kaissling, 1987). Possibly, this temporal discrepancy results from the heterologous expression systems used. Alternatively, these currents serve other purposes, such as the modulation of spontaneous activity shown in fruitflies (review: Nakagawa and Vosshall, 2009). The function of the COR is not easy to resolve since specific blockers are missing which solely delete the ionotropic component of the current leaving its chaperon function intact. Because the COR functions as a chaperon which is required for insertion of ORs into dendritic membranes (Larsson et al., 2004) deletions of the COR will delete odor responses and will not necessarily provide evidence for the need of ionotropic odor transduction cascades.

In conclusion: Only two reports using unphysiologically high stimulus concentrations and vertebrate expression systems for fruitfly ORs are in support of a solely ionotropic signal transduction cascade, which, however, is much slower than odor transduction in situ. As an alternative hypothesis I suggest that cyclic nucleotidedependent, leaky heteromeric OR/COR complexes are involved in a depolarizing influx of $\mathrm{Ca}^{2+}$ and other cations into ORNs to drive spontaneous subthreshold membrane potential oscillations and, thus, spontaneous activity daytime-dependently (Figure 2). Subthreshold membrane potential oscillations keep ORNs close to the action potential threshold and constitute a temporal filter. Thus, they control sensitivity as well as temporal response characteristics of ORNs. Future experiments will examine whether the modulation of the heteromeric OR/COR complexes via a cyclic nucleotide-binding domain on the COR is instrumental for the regulation of daytime-dependent temporal resolution of the ORNs via hormones, neuropeptides, and biogenic amines (Flecke and Stengl, 2009). Therefore, many more studies in different species are needed to resolve the function of the OR/COR complexes for insect olfactory transduction.

\section{G-PROTEIN COUPLED PHOSPHOLIPASE C $\beta$-DEPENDENT ODOR TRANSDUCTION CASCADES}

Many studies obtained with various techniques from different laboratories support the role of colocalized heterotrimeric G-proteincoupled signal transduction cascades in insect ORNs. Most evidence is provided for a phospholipase C $\beta$ (PLC $\beta$ )-dependent signal transduction cascade (Figure 3). Overwhelming evidence suggest that it underlies the sensitive phasic pheromone responses of the males late at night during their search for the female. In contrast, secondlong, strong pheromone stimuli appear to decrease the sensitivity of the ORNs and involve protein kinase C (PKC)-dependent actions which appear to downregulate and terminate PLC $\beta$-dependent signal transduction (Stengl, 1993, 1994; Schleicher et al., 1994).

In different insects cloning experiments, in situ hybridizations, and also immunocytochemical studies provided evidence for the presence of $G_{s}$ (which activates adenylyl cyclase), $G_{i}$ (which inhibits adenylyl cyclase), $\mathrm{G}_{\mathrm{q}}$ (which activates phospholipase $C \beta$ ), and $\mathrm{G}_{\mathrm{o}}$ (which targets are not well characterized) in antennae (Raming et al., 1989; Boekhoff et al., 1990; Talluri et al., 1995; Laue et al., 1997; Schmidt et al., 1998; Kalidas and Smith, 2002; Miura et al., 2005; Rützeler and Zwiebel, 2005; Kain et al., 2008; Chatterjee et al., 2009; Boto et al., 2010). Four G-proteins: $G_{s}, G_{i}, G_{q / 11}, G_{\beta 13 F}$ were colocalized in dendrites of ORNs of D. melanogaster (Boto et al., 2010). In addition, $G_{o}$ is present in fruitfly ORNs, increasing their sensitivity to all odors tested (Chatterjee et al., 2009). Also in the silkmoth B. mori application of G-protein activating fluoride increased activity in single pheromone-sensitive sensilla (Laue et al., 1997). Because $\mathrm{G}_{\mathrm{q}}$ was located via molecular cloning studies and in immunocytochemical experiments in dendrites of B. mori, Antheraea pernyi, and Mamestra brassicae, fluoride appeared to activate PLC $\beta$ (Jacquin-Joly et al., 2002).

Also other studies support a pheromone-transduction cascade via PLC $\beta$ which hydrolyzes phospholipids generating inositol trisphosphate $\left(\mathrm{IP}_{3}\right)$ and diacylglycerol (DAG). The enzyme PLC $\beta$ was cloned and in situ hybridizations showed that PLC $\beta$ is transcribed in adult pheromone-sensitive ORNs of the moth Spodoptera littoralis (Chouquet et al., 2010). In addition, immunocytochemical studies located a PLC $\beta$-subtype in homogenates of isolated pheromonesensitives sensilla of $A$. polyphemus (Maida et al., 2000). This PLC $\beta$ appears to mediate insect odor transduction, because odor-dosedependently physiological concentrations and time courses of pheromones as well as general odors caused rapid, transient rises of $\mathrm{IP}_{3}$ in antennal homogenates within several milliseconds. The $\mathrm{IP}_{3}$ rises occur in the dendritic fraction of antennal tissue in the same millisecond time window as phasic odor-dependent action potential responses to brief, millisecond-long physiological stimuli (Breer et al., 1990; Boekhoff et al., 1993; Kaissling and Boekhoff, 1993). Consistently, $\mathrm{IP}_{3}$-receptors were located in the dendritic membrane of moth ORNs (Laue and Steinbrecht, 1997). In addition, perfusion of cultured ORNs from $M$. sexta with $\mathrm{IP}_{3}$ opened a specific sequence of at least three inward currents which resembled pheromone-dependent currents (Figure 3; Stengl et al., 1992; Stengl, 1993, 1994). Pheromone opened a very transient $\mathrm{IP}_{3}$-dependent $\mathrm{Ca}^{2+}$ current (\#9, Figure 3) which is blocked via intracellular $\mathrm{Ca}^{2+}$ rises within less than $50 \mathrm{~ms}$. The rise in $\mathrm{Ca}^{2+}$ rapidly opens a $\mathrm{Ca}^{2+}$-activated cation channel (\#10) which is blocked within seconds via further intracellular $\mathrm{Ca}^{2+}$ rises. In addition, the increase in $\mathrm{Ca}^{2+}$ opens fast, large $\mathrm{Ca}^{2+}$-dependent $\mathrm{K}^{+}$channels (\#4) and a $\mathrm{Cl}^{-}$channel (\#7) possibly involved in re-/hyperpolarization of the receptor potential (Dolzer et al., 2008; Pézier et al., 2007, 2010). When the receptor potential reaches spike threshold $\mathrm{Na}^{+}$influx occurs at the spike initiation zone of the axon. Then, voltage-sensitive $\mathrm{K}^{+}$channels $(\# 5,6)$ and possibly also second messenger-dependent $\mathrm{K}^{+}-(\# 4,8)$ and $\mathrm{Cl}^{-}$-channels $(\# 7)$ repolarize and guarantee phasic pheromone responses (Zufall et al., 1991a). In cell-attached patch clamp recordings of ORNs from $M$. sexta as the first pheromone-response an increase in the open probability of the ATP/cGMP-blocked $\mathrm{K}^{+}$ 


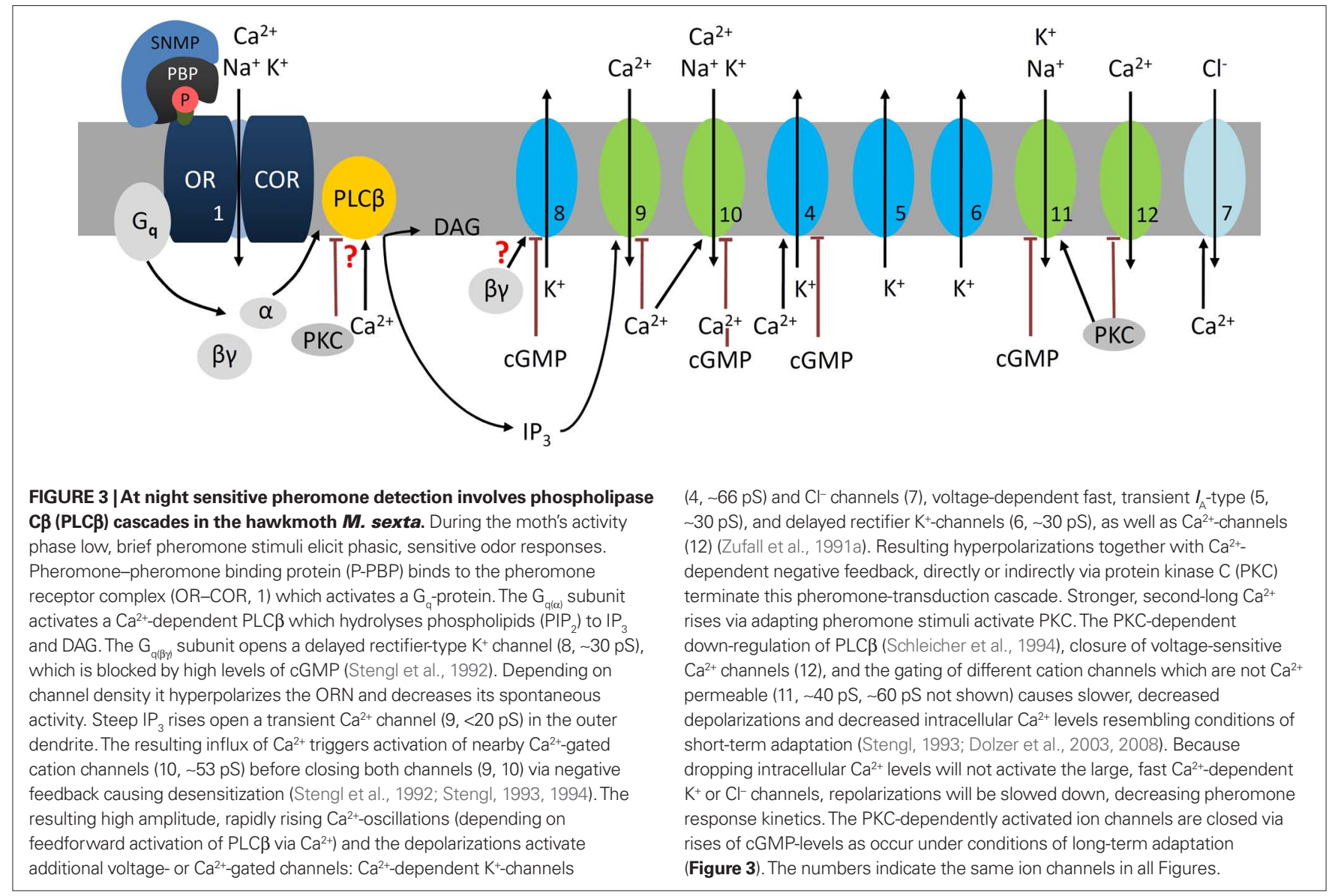

channel (\#4, Figure 3) was observed (Stengl et al., 1992). Thus, this channel might be opened via $\mathrm{G}_{\beta \gamma}$ subunits and might be present in the outer dendrite, in contrast to the voltage-dependent $\mathrm{K}^{+}$ channels which rather might be located in the soma and axon compartments (Stengl et al., 1992). It remains to be examined whether this channel (\#8) is employed in pheromone-dependent hyperpolarizations as observed in intracellular recordings of ORNs in vitro (Stengl, 1990). In contrast, $\mathrm{IP}_{3}$ was ineffective in excised inside-out patches of dendritic membranes from silkmoth ORNs, very likely because $\mathrm{IP}_{3}$-dependent ion channels were blocked $\mathrm{Ca}^{2+}$ dependently via sustained, adapting incubation with pheromone (Zufall and Hatt, 1991).

Next to IP, DAG is also a potential second messenger of odor transduction in moths. It appears to serve different functions, either as activator of PKC (Figure 3) or as activator of transient receptor potential (TRP)-type ion channels (not shown). Immunocytochemical experiments provided evidence for the colocalization of phospholipase $C \beta$ together with a PKC in trichoid sensilla of A. polyphemus (Maida et al., 2000). The PKC appears to be employed in transduction of long, adapting pheromone stimuli because in homogenates of antennal sensilla of $A$. polyphemus second- to minute-long incubation with pheromone increased PKC but not PKA activity (Maida et al., 2000). Also, constant, second- to minute-long presence of low pheromone concentrations in extruded dendrites of trichoid sensilla from A. polyphemus cation channels were activated which resembled
DAG-, PKC- and cGMP-dependently activated channels (Zufall and Hatt, 1991). In addition, DAG application in situ and in vitro in tip recordings and patch clamp recordings depolarized ORNs or activated depolarizing inward currents in B. mori, A. polyphemus, and M. sexta (Maida et al., 2000; Pophof and van der Goes van Naters, 2002; Krannich, 2008). Since in biochemical assays PKC activation decreased PLC $\beta$-activity and rendered it less transient PKC may play a role for gain control and down-regulation of pheromone responses under conditions of overstimulation, possibly resembling conditions of short-term adaptation (Schleicher et al., 1994). In accordance with this notion PKC activity appears to underlie pheromone-dependent currents activated via second- to minute-long adapting pheromone application in patch clamp recordings in vitro (Stengl, 1994; Dolzer et al., 2008). Thus, activation of PKC appears to guarantee signal termination and adjustment of responsiveness of ORNs under conditions of strong, long-lasting $\mathrm{Ca}^{2+}$ rises which close $\mathrm{IP}_{3}-$ and $\mathrm{Ca}^{2+}$-activated channels. Because PKC closes voltagesensitive $\mathrm{Ca}^{2+}$ channels and opens cation channels which are not $\mathrm{Ca}^{2+}$-permeable PKC activity decreases intracellular $\mathrm{Ca}^{2+}$ concentrations (Dolzer et al., 2008). Thus, the PKC-dependent cascade favors conditions of low intracellular $\mathrm{Ca}^{2+}$ and will not trigger opening of large $\mathrm{Ca}^{2+}$-dependent $\mathrm{K}^{+}$or $\mathrm{Cl}^{-}$channels. Therefore, ORNs will repolarize more slowly and will show less phasic, reduced action potential frequencies, as observed during conditions of short-term adaptation. 
In contrast, other work suggests that DAG can also activate a PKC-independent pathway. A PKC-independent DAG-gated cation current was described in patch clamp recordings from cultured ORNs of S. littoralis and M. sexta (Lucas and Pézier, 2006; Krannich, 2008). In accordance, a diacylglycerol kinase (which converts DAG to phosphatidic acid and recycles phosphatidylinositols) was located in olfactory sensilla trichodea of $S$. litt ralis (Chouquet et al., 2008). Because $\mathrm{IP}_{3}$ - and DAG-gated ion channels most likely belong to the TRP-superfamily of ion channels (review: Dong et al., 2010) the localization of TRP channels in moth antennae further substantiates the importance of the PLC $\beta$-dependent signal transduction pathway in moth olfaction (Ackermann, 2004; Chouquet et al., 2009). A PLC $\beta$-dependent cascade might be employed not only in pheromone-transduction but also in general odor transduction. This is supported by an $\mathrm{IP}_{3}$ dependent conductance, measured in locusts, which resembled a general odor-dependent conductance (Wegener et al., 1997). This assumption is further supported by patch clamp experiments of M. sexta ORNs in vitro. While $36 \%$ of all M. sexta ORNs in culture responded to pheromone, more than $90 \%$ of the cultured ORNs responded to GTP $\gamma \mathrm{S}$ (activator of G-protein-dependent cascades), more than $90 \%$ responded to $\mathrm{IP}_{3}$, and about $64 \%$ responded to DAG with inward currents (Stengl, 1993, 1994; Krannich, 2008). These findings indicate that in M. sexta both, ORNs which respond to pheromone as well as ORNs which respond to general odors use G-protein-coupled metabotropic signal transduction cascades via activation of a PLC $\beta$ (Stengl et al., 1999). Because the number of food odor-sensitive ORNs correlated with the number of DAGresponsive cells in vitro it needs to be examined whether food odordependent ORNs in M. sexta employ DAG-gated TRP-channels, instead of $\mathrm{IP}_{3}$-gated channels. Whether pheromone transduction in the hawkmoth employs both dendritic $\mathrm{IP}_{3}$ - and DAG-gated ion channels remains to be examined.
In conclusion: There is convincing evidence, provided by many groups based upon different techniques, for sensitive, phasic PLC $\beta$ dependent signal transduction cascades in pheromone- and also in general odor transduction in moths (Figure 3). Apparently, $\mathrm{IP}_{3}-$, DAG-, and $\mathrm{Ca}^{2+}$-gated TRP-like ion channels underlie fast, phasic responses to millisecond-long, weak odor stimuli. Desensitization (=the decline of the response during ongoing stimulation) via $\mathrm{Ca}^{2+}$ dependent negative feedback allows for phasic action potential responses. Stronger or longer odor stimuli cause short-term adaptation via longer-lasting $\mathrm{Ca}^{2+}$ rises which activate PKC. Activation of $\mathrm{PKC}$ reduced $\mathrm{Ca}^{2+}$ influx and slowed down odor responses shifting from phasic to more tonic response patterns. Furthermore, elevation of cGMP levels inactivated PLC $\beta$-dependent signal transduction cascades (Stengl et al., 2001). Thus, depending on stimulus length and strength different second messengers determine threshold and kinetics of the odor response.

\section{cGMP-DEPENDENT ODOR TRANSDUCTION CASCADES IN MOTH ORNs}

Different studies suggested that cGMP-dependent signal transduction cascades in moth olfaction are employed for long-term adaptation of the olfactory system during minute-long or very strong odor exposure (Figure 4). Several different types of GCs were cloned and characterized from hawkmoth antennae and in situ hybridization located some of them to ORNs (Simpson et al., 1999; Nighorn et al., 2001; Stengl et al., 2001; Morton and Nighorn, 2003; Morton, 2004). In homogenates of different insect antennae only very strong, long pheromone stimuli caused delayed, slow rises of cGMP (Ziegelberger et al., 1990; Boekhoff et al., 1993). Immunocytochemistry revealed that pheromone-dependent cGMP-rises occurred in neuronal and nonneuronal cells of pheromone-sensitive trichoid sensilla (Stengl et al., 2001). The cGMP rises in ORNs strongly depended on

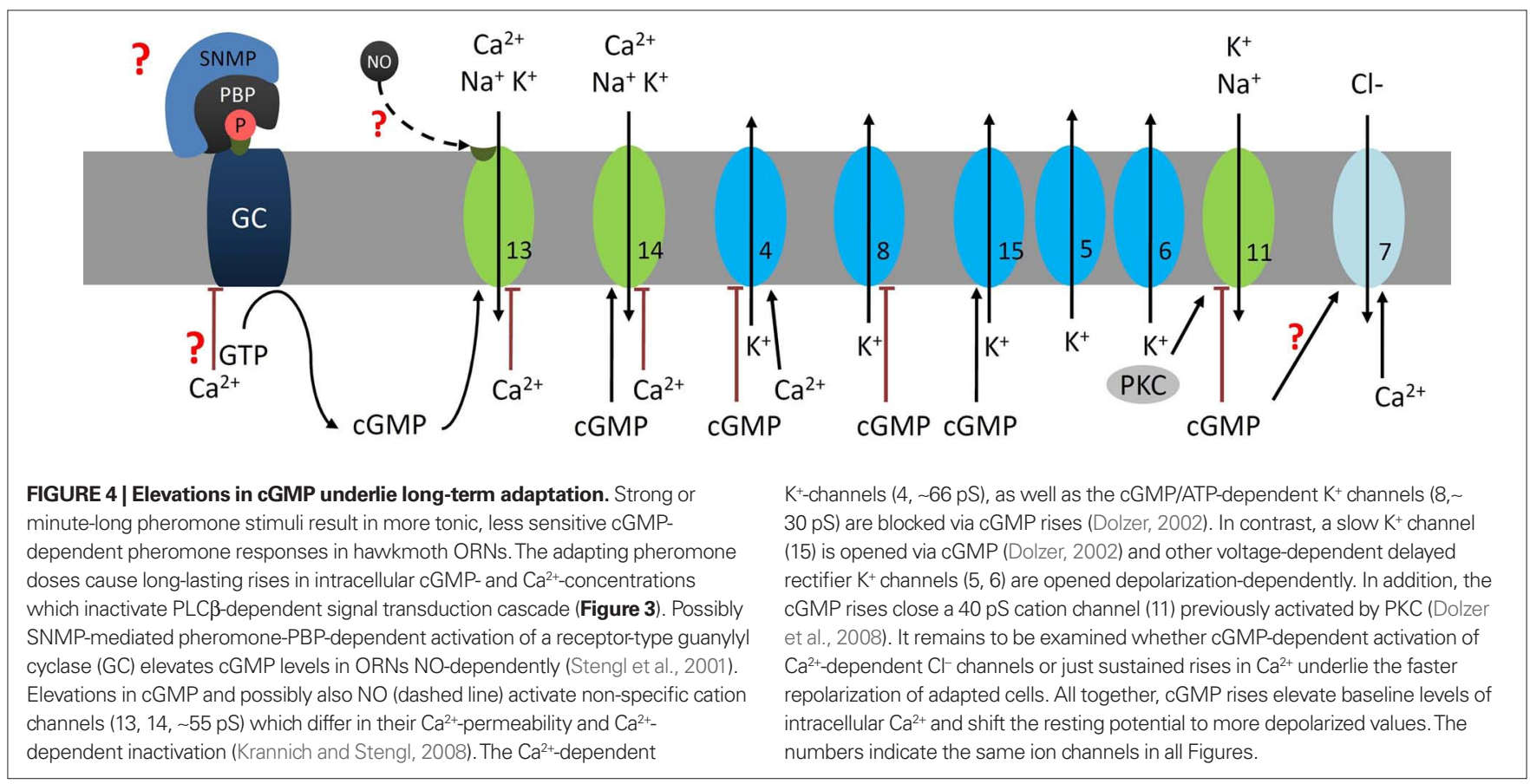


the duration and strength of the pheromone stimulus, as well as on the presence of nitric oxide (NO). Because in situ hybridizations showed that NO-dependent soluble GCs are not expressed in pheromone-sensitive ORNs it is likely that NO opened $\mathrm{Ca}^{2+}$ permeable CNG channels instead (Figure 4, \#13; Broillet and Firestein, 1997; Stengl et al., 2001). The elevated cGMP-levels close fast $\mathrm{K}^{+}$channels (Figure 4, \#8), large, fast $\mathrm{Ca}^{2+}$-activated $\mathrm{K}^{+}$ channels (\#4), as well as PKC-dependent ion channels (Figure 4, \#11), while opening slower $\mathrm{K}^{+}$channels (\#15) and less transient $\mathrm{Ca}^{2+}$-permeable cation channels $(\# 13,14)$ in moth ORNs (Zufall and Hatt, 1991; Zufall et al., 1991a; Stengl, 1994; Dolzer, 2002; Dolzer et al., 2008; Krannich and Stengl, 2008). Because cGMP-infusion into trichoid sensilla decreased the pheromonedependent action potential frequency daytime-dependently and rendered pheromone responses less phasic, cGMP rises adapt and slow down ORNs (Flecke et al., 2006). Interestingly, there is considerable cross-talk between PLC $\beta$ - and GC-dependent signal transduction cascades because cGMP affected $\mathrm{Ca}^{2+}$-activated and PKC-activated ion channels (Zufall et al., 1991a,b; Dolzer et al., 2008). Based on our data obtained from tip recordings (Dolzer et al., 2003; Flecke et al., 2006) and biochemical assays I propose that in insects endogenous cGMP elevations during the inactivity phase are at least partially responsible for increased odor-thresholds and decreased ability to resolve odor pulses (Figure 5). In addition, it needs to be examined whether resting moths can be disadapted via octopamine-mediated stressors. Possibly, fast, large $\mathrm{Ca}^{2+}$ transients due to stress hormone release during the inactivity phase inhibit receptor-GCs and activate phosphodiesterases to decrease cGMP levels. Finally, it remains to be examined whether receptor-GCs in moth ORNs are activated SNMP-dependently via PBP-dimers loaded with pheromone.

In conclusion: Very strong, long pheromone stimuli are possibly encountered in close contact with the female moth causing conditions of long-term olfactory adaptation in the male. These adapting stimuli can be detected via cGMP-dependent signal transduction cascades. The cGMP-dependent odor transduction cascades (Figure 4) appear to exclude PLC $\beta$-dependent cascades and result in less sensitive, less phasic pheromone responses as compared to $\mathrm{IP}_{3}^{-}$, DAG-, $\mathrm{Ca}^{2+}-$, or PKC-dependent responses (Stengl et al., 1992; Dolzer, 2002; Dolzer et al., 2008). Circadian rhythms of cGMP baseline levels could regulate activity-rest cycles of moths (Figure 5).

\section{OCTOPAMINE AND CAMP-DEPENDENT TRANSDUCTION CASCADES IN MOTH ORNS}

While in vertebrates a cAMP-dependent odor transduction cascade is predominant in the main olfactory epithelium, in moths there is less evidence for cAMP-dependent signal transduction cascades (review; Fleischer et al., 2009; Kaupp, 2010). However, in moth antennae octopamine receptors were cloned which appear to couple to adenylyl cyclases (Von Nickisch-Rosenegk et al., 1996; Dacks et al., 2006; Huang et al., 2008). Biochemical experiments showed that hemolymph concentration of the stress hormone octopamine express endogenous circadian rhythms with its maximal concentration during the activity phase of the moths late at night (Lehman, 1990). In addition, octopaminergic neurons project into the antenna and appear to contact

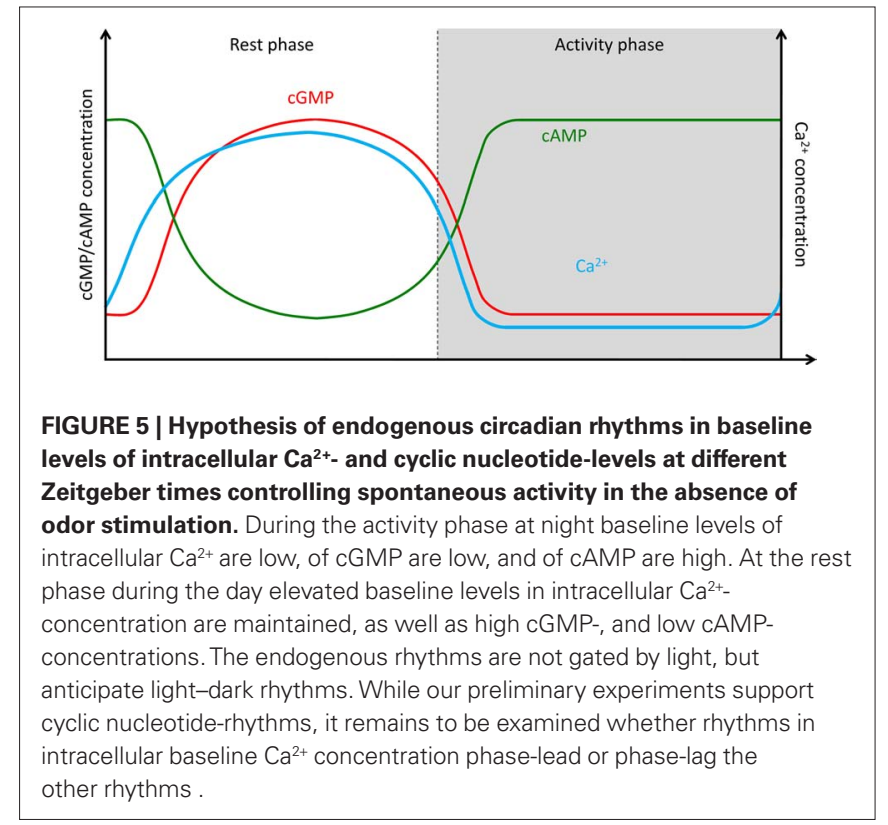

ORNs. In different moth species octopamine improves pheromone source location daytime-dependently in behavioral studies (Linn Jr. and Roelofs, 1986). Octopamine disadapts ORNs and renders pheromone responses more phasic, apparently via a cAMP-dependent transduction cascade and an additional possibly $\mathrm{Ca}^{2+}$-dependent cascade in tip recordings of intact trichoid sensilla (Pophof, 2000, 2002; Flecke and Stengl, 2009; Flecke et al., 2010). In addition, octopamine increased the spontaneous activity of the pheromone-sensitive ORNs. This increase was only partly mimicked by cAMP-rises (Figure 2; Flecke and Stengl, 2009; Flecke et al., 2010). Possibly, cAMP increased the open probability of the leaky OR/COR ion channel complex as reported in the fruitfly (Wicher et al., 2008). The leaky OR/COR (Figure 2, \#1) would cause a steady influx of $\mathrm{Ca}^{2+}$ into ORNs pulling the membrane potential to more depolarized potentials while increasing baseline $\mathrm{Ca}^{2+}$ concentrations. In addition cAMP would cause superimposed transient $\mathrm{Ca}^{2+}$-rises via opening of a very transient, $\mathrm{PKC}$-inhibited L-type $\mathrm{Ca}^{2+}$-channel (\#2) and a less transient CNG-channel (\#3) both of which would transiently depolarize ORNs (Krannich and Stengl, 2008). The rapid, transient $\mathrm{Ca}^{2+}$ rises as well as the resulting depolarizations would initiate repolarizations via activation of voltage-dependent $\mathrm{K}^{+}$ channels $(\# 5,6)$, and fast, large $\mathrm{Ca}^{2+}$ dependent $\mathrm{K}^{+}-(\# 4)$ and $\mathrm{Cl}^{-}$ channels (Figure 2, \#7). Thus, OA would increase subthreshold membrane potential oscillations in amplitude and frequency, which might underlie the observed OA-dependent increase in spontaneous activity (Flecke and Stengl, 2009). It remains to be examined whether the OA-dependent decrease in odor threshold and the increased odor-response kinetics are due to second messenger-dependent modulation of subthreshold membrane potential oscillations.

In conclusion: So far, no odor-dependent cAMP-rises were described in moths. But the stress hormone octopamine couples via $G_{s}$ to adenylyl cyclase in moth antennae. Thus, endogenous, circadian rhythms in octopamine concentration possibly generate 
circadian rhythms of cAMP baseline levels in ORNs. Possibly together with activation of a $\mathrm{G}_{\mathrm{q}}$-protein dependent pathway (not shown in Figure 2) octopamine allows for more phasic, more sensitive pheromone responses during the night (Figure 2) (Flecke and Stengl, 2009; Flecke et al., 2010). In addition, octopamine can also acutely elevate cAMP-concentrations in antennae in response to stressors at all daytimes via centrifugal octopaminergic neurons. Stress-dependent activation of these octopaminergic cells during the day disadapts ORNs and allows for pheromone responses of awakened moths. Whether OA-dependent cAMP rises in synergism with specific $\mathrm{Ca}^{2+}$ levels increase the spontaneous activity of ORNs and, thus, improve their ability to follow high frequency odor pulses, remains to be examined.

\section{ARE THERE SIGNALOSOMES IN INSECT OLFACTION?}

The dispute over rapid ionotrophic versus signal enhancing metabotropic signal transduction cascades can be boiled down to the question whether there is a need for speed or a need for sensitivity maximization in pheromone transduction. While ionotropic signal transduction cascades work in the microsecond time range and are employed, e.g., in the auditory system, metabotropic cascades are employed to allow for signal amplification and response range enlargement such as in the visual system. In the fruitfly visual system where scaffolding proteins aggregate the members of the metabotropic signal transduction cascade to form fast-acting signalosomes reaction times as fast as $20 \mathrm{~ms}$ are reached (Hardie and Raghu, 2001). Thus, the response time of signalosome-employing metabotropic signal transduction cascades would be in the time range maximally employed by the insect olfactory system. In addition, sensitivity maximization allowing for the detection of single pheromone molecules as calculated by Kaissling (1987) cannot be reached with an ionotropic cascade but requires signal amplification via metabotropic cascades. So far, it is not known yet, whether insect olfactory signal transduction cascades are spatially aggregated via scaffolding molecules to form fast-acting signalosomes (Hardie and Raghu, 2001). However, scanning electron microscopy and atomic force microscopy could resolve large complexes of molecules in the outer dendritic membrane of moth ORNs of the moths A. polyphemus and A. pernyi (Klein and Keil, 1984; Eschrich et al., 1998). Next to different pores of $14-18 \mathrm{~nm}$ diameter with a density of about $20 / \mu \mathrm{m}^{2}$ also dots and membrane patches could be resolved. It remains to be examined whether these dots and patches are signalosomes, which could speed up metabotropic signal transduction machinery. The presence of signalosomes is supported by patch clamp analysis of ORNs which suggests close local neighborhood of different pheromone-dependent ion channels and enzymes which remained together after patch excision (Stengl, 1993, 1994). In addition, scaffolding molecules were cloned from antennae of the hawkmoth. But still, the presence of signalosomes in insect olfaction remains to be examined.

To summarize: Moth pheromone transduction requires reaction times in the range of $30 \mathrm{~ms}$, large, adaptable dynamic range, and extreme sensitivity maximization. Thus, signalosome-dependent metabotropic signal transduction cascades would fit these requirements best.

\section{CONCLUSIONS}

Accumulating evidence suggests that there is not only one predominant odor transduction cascade in insect olfactory sensory neurons. Rather, there are different colocalized, equally important signal transduction cascades which allow for sliding adjustment of odor response threshold and kinetics, in response to endogenous physiological rhythms, to different behavioral states, and to various different odor stimulus properties (Figures 2-5). Preliminary evidence suggests that endogenous circadian rhythms of cyclic nucleotides occur in insect ORNs, synchronized with the activity-rest cycle of the insect with maximal cAMP concentrations during the activity phase and maximal cGMP concentrations during the rest phase (Figure 5). Elevated cGMP levels increase baseline levels of intracellular $\mathrm{Ca}^{2+}$. Thus, a circadian rhythm in the baseline of intracellular $\mathrm{Ca}^{2+}$ concentrations, with the maximum at rest, during the day would accompany cyclic nucleotide rhythms. Whether additional mechanisms control rhythms in intracellular $\mathrm{Ca}^{2+}$ levels and whether circadian rhythms in intracellular baseline $\mathrm{Ca}^{2+}$ concentrations phase-lead or phase-lag cyclic nucleotide rhythms remains to be examined. Hormones and possibly also neuropeptides which represent a specific physiological, metabolic state such as hunger or sexual drive might couple to $G_{i}$ or $G_{s}$, and possibly also to receptor GCs, thereby changing baseline levels of the respective second messengers. Superimposed on these slow rhythms of the baseline levels of cyclic nucleotide- and $\mathrm{Ca}^{2+}$ concentrations high frequency, large amplitude oscillations of the respective second messengers occur during odor "sniffing" with each stroke of the wings in flight. These ultradian oscillations depend on strength and time course of odor stimuli. The resulting relative concentration ratios of intracellular messengers and activated enzymes then open or close different ion channels and, thus, define the response threshold and temporal resolution of ORNs. Therefore, for each internal physiological state and each external stimulus condition there is a specific ratio of these second messengers and activated enzymes, and a corresponding complementary set of depolarizing and hyperpolarizing ion channels which support odor responses. This model differs greatly from current models of insect odor transduction (Gu et al., 2009; Nakagawa and Vosshall, 2009) and needs to be challenged in computational simulations to allow for quantitative predictions.

But what is the role of the "ionotropic" pathway via OR/ COR-dependent ion channels in moth ORNs? I suggest that the main function of this metabotropically mediated OR/ COR-ion channel complex is the control of subthreshold membrane potential oscillations and thus of the spontaneous activity of ORNs to allow for temporal encoding of odor blends. However, more comparative work in different insect species needs to be accomplished to resolve its functions and to challenge my hypothesis.

\section{ACKNOWLEDGMENTS}

Thanks to Dr. Uwe Homberg, Dr. Christian Flecke, Andreas Nolte, Ursula Reichert, and to the referees for critically reading and improving of the manuscript. All Figures were generously provided by Andreas Nolte. The research was supported by grants from the Deutsche Forschungsgemeinschaft (DFG). 


\section{REFERENCES}

Ackermann, F. (2004). Ionenkanäle in der Antenne des Tabakschwärmers Manduca sexta. Identifizierung eines Homologs der TRP-Kanalfamilie. Dissertation, University of Marburg.

Almaas, T. J., Christensen, T. A., and Mustaparta, H. (1991). Chemical communication in heliothine moths. I. Antennal receptor neurons encode several features of intra- and interspecific odorants in the male corn earworm moth Helicoverpa zea. J. Comp. Physiol. A 169, 249-258.

Altner, H., and Prillinger, L. (1980). Ultrastructure of invertebrate chemo-, thermo-, and hygroreceptors and its functional significance. Int. Rev. Cytol. 67, 69-139.

Baker, T. C., Hansson, B. S., Löfstedt, C., and Löfquvist, J. (1988). Adaptation of antennal neurons in moths is associated with cessation of pheromonemediated upwind flight. Proc. Natl. Acad. Sci. U.S.A. 85, 9826-9830.

Baker, T.C., and Haynes, K. F. (1989). Field and laboratory electroantennographic measurements of pheromone plume structure correlated with oriental fruit moth behavior. Physiol. Entomol. 14, 1-12.

Baker, T. C., and Vogt, R. G. (1988). Measured behavioral latency in response to sex-pheromone loss in the large silk moth Antheraea polyphemus. J. Exp. Biol. 137, 29-38.

Baker, T. C., Willis, M., Haynes, K. F., and Phelan, P. L. (1985). A pulsed cloud of sex pheromone elicits upwind flight in male moths. Physiol. Entomol. 10, 257-265.

Benton, R. (2009). Evolution and revolution in odor detection. Science 326, 282-283.

Benton, R., Sachse, S., Michnick, S. W., and Vosshall, L. B. (2006). Atypical membrane topology and heteromeric function of Drosophila odorant receptors in vivo. PLoS Biol. 4, e20. doi: 10.1371/ journal.pbio.0040020

Benton, R., Vannice, K. S., and Vosshall, L. B. (2007). An essential role for a CD36-related receptor in pheromone detection in Drosophila. Nature 450, 289-293.

Boekhoff, I., Seifert, E., Göggerle, S., Lindemann, M., Krüger, B.-W., and Breer, H. (1993). Pheromone-induced second messenger signalling in insect antennae. Insect Biochem. Mol. Biol. 23, 757-762.

Boekhoff, I., Strotmann, J., Raming, K., Tareilus, E., and Breer, H. (1990). Odorant-sensitive phospholipase $\mathrm{C}$ in insect antennae. Cell. Signal. 2, 49-56.

Boto, T., Gomez-Diaz, C., and Alcorta, E. (2010). Expression analysis of the 3 G-protein subunits, $G_{\alpha}, G_{\beta}, G_{\gamma}$, in the olfactory receptor organs of adult Drosophila melanogaster. Chem. Senses 35, 183-193.

Breer, H., Boekhoff, I., and Tareilus, E. (1990). Rapid kinetics of second messenger formation in olfactory transduction. Nature 345, 65-68.

Brigaud, I., Montagne, N., Monsempes, C., Francois M.-C., and Macquin-Joly, E. (2009). Identification of an atypical insect olfactory receptor subtype highly conserved within noctuids. FEBS J. 276, 6537-6547.

Broillet, M.-C., and Firestein, S. (1997). $\beta$ Subunits of the olfactory cyclic nucleotide-gated channel form a nitric oxide activated $\mathrm{Ca}^{2+}$ channel. Neuron 18, 951-958.

Chatterjee, A., Roman, G., and Hardin, P. E. (2009). G contributes to olfactory reception in Drosophila melanogaster. BMC Physiol. 9, 1-7. doi: 10.1186/1472-6793-9-22

Chouquet, B., Bozzolan, R., Solvar, M., Duportets, L., Jacquin-Joly, E., Lucas, P., and Debernard, S. (2008). Molecular cloning and expression patterns of a putative olfactory diacylglycerol kinase from the noctuid moth Spodoptera littoralis. Insect Mol. Biol. 17, 485-493.

Chouquet, B., Debernard, S., Bozzolan, R., Solvar, M., Maibeche-Coisne, M., and Lucas, P. (2009). A TRP channel is expressed in Spodoptera littoralis antennae and is potentially involved in insect olfactory transduction. Insect Mol. Biol. 18, 213-222.

Chouquet, B., Lucas, P., Bozzolan, R., Solvar, M., Maibeche-Coisne, M., Durand, N., and Debernard, S. (2010). Molecular characterization of a phospholipase $\mathrm{C}$ \{beta\} potentially involved in moth olfactory transduction. Chem. Senses. 35, 363-373.

Dacks, A. M., Dacks, J. B., Christensen, T. A., and Nighorn, A. J. (2006). The cloning of one putative octopamine receptor and two putative serotonin receptors from the tobacco hawkmoth Manduca sexta. Insect Biochem. Mol. Biol. 36, 741-747.

De Bruyne, M., and Baker, T. C. (2008). Odor detection in insects: volatile codes. J. Chem. Ecol. 34, 882-897.

De Bruyne, M., Foster, K., and Carlson, J.R. (2001). Odor coding in the Drosophila antenna. Neuron 30, 537-552.

Dolzer, J. (2002). Mechanisms of Modulation and Adaptation in Pheromone-Sensitive Trichoid Sensilla of the Hawkmoth Manduca sexta. Dissertation, University of Marburg, $1-120$.

Dolzer, J., Fischer, K., and Stengl, M. (2003). Adaptation in pheromonesensitive trichoid sensilla of the hawkmoth Manduca sexta. J. Exp. Biol. 206, 1575-1588.
Dolzer, J., Krannich, S., Fischer, K, and Stengl, M. (2001). Oscillations of the transepithelial potential of moth olfactory sensilla are influenced by octopamine and serotonin. J. Exp. Biol. 204, 2781-2794.

Dolzer, J., Krannich, S., and Stengl, M. (2008). Pharmacological investigation of protein kinase $\mathrm{C}$ and cGMPdependent ion channels in cultured olfactory receptor neurons of the hawkmoth Manduca sexta. Chem. Senses 33, 803-813.

Dong, X.-P., Wang, X., and Xu, H (2010). TRP channels of intracellular membranes. J. Neurochem. 1013 313-328.

Duchamp-Viret, P., Kostal, L., Chaput, M. Lansky, P., and Rospars, J. P. (2005). Patterns of spontaneous activity in single rat olfactory receptor neurons are different in normally breathing and tracheotomized animals. J. Neurobiol. 65, 97-114.

Eschrich, R., Kumar, G. L., Keil, T. A., and Guckenberger, R. (1998). Atomicforce microscopy on the olfactory dendrites oft he silkmoths Antheraed polyphemus and A. pernyi. Cell Tissue Res. 294, 179-185.

Flecke, C., Dolzer, J., and Stengl, M. (2006). Perfusion with cGMP adapts the action potential response in pheromone-dependent trichoid sensilla in the moth Manduca sexta. J. Exp. Biol. 209, 3898-3912.

Flecke, C., Nolte, A., and Stengl, M. (2010). Perfusion with cAMP analog affects pheromone-sensitive trichoid sensilla of the hawkmoth Manduca sexta in a time-dependent manner. J. Exp. Biol. 213, 842-852.

Flecke, C., and Stengl, M. (2009) Octopamine and tyramine sensitize pheromone-sensitive olfactory sensilla of the hawkmoth Manduca sexta in a daytime-dependent manner. J. Comp. Physiol. A 195, 529-545.

Fleischer, J., Breer, H., and Strotmann, J. (2009). Mammalian olfactory receptors. Front. Cell. Neurosci. 3:9. doi: 10.3389/neuro.03.009.2009

Forstner, M., Breer, H., and Krieger, J. (2009). A receptor and binding protein interplay in the detection of a distinct pheromone component in the silkmoth Antheraea polyphemus. Int. J. Biol. Sci. 5, 745-757.

Forstner, M., Gohl, T., Breer, H., and Krieger, J. (2006). Candidate pheromone binding proteins of the silkmoth Bombyx mori. Invert. Neurosci. 6, 177-187.

Forstner, M., Gohl, T., Gondesen, I., Raming, K., Breer, H., and Krieger, J. (2008). Differential expression of SNMP-1 and SNMP-2 proteins in pheromone-sensitive hairs of moths. Chem. Senses 33, 291-299.
Gesteland, R. C. (1971). "Neural coding in olfactory receptor cells," in Handbook of Sensory Physiol, Vol. IV, Chem. Senses, ed. L. M. Beidler (Berlin: Springer), 132-150.

Grosse-Wilde, E., Gohl, T., Bouche, E., Breer, H., and Krieger, J. (2007). Candidate pheromone receptors provide the basis for the response of distinct antennal neurons to pheromonal compounds. Eur. J. Neurosci. 25, 2364-2373.

Grosse-Wilde, E., Svatos, A., and Krieger, J. (2006). A pheromone-binding protein mediates the bombykol-induced activation of a pheromone receptor in vitro. Chem. Senses 31, 547-555.

Gu, Y., Lucas, P., and Rospars, J.-P. (2009). Computational model of the insect pheromone transduction cascade. PLoS Comput. Biol. 5, e1000321. doi: 10.1371/journal.pcbi.1000321

Hardie, R. C., and Raghu, P. (2001). Visual transduction in Drosophila. Nature 413, 186-193.

Huang, J., Hamasaki, T., Ozoe, F., and Ozoe, Y. (2008). Single amino acid switch for distinct $G$ protein couplings. Biochem. Biophys. Res. Commun. 371, 610-604.

Itagaki, H., and Conner, W. E. (1988). Calling behavior of Manduca sexta (Lepidoptera: Sphingidae) with notes on the morphology of the female sex pheromone gland. Ann. Entomol. Soc. Am. 81, 798-807.

Ito, I., Bazhenov, M., Ong, R. C., Raman, B., and Stopfer, M. (2009). Frequency transitions in odor-evoked neural oscillations. Neuron 64, 692-706.

Ito, I., Ong, R. C., Raman, B., and Stopfer, M. (2008). Olfactory learning and spike timing dependent plasticity. Commun. Integr. Biol. 1, 170-171.

Jacquin-Joly, E., Francois, M. C., Burnet, M. Lucas, P., Bourrat, F., and Maida, R. (2002). Expression pattern in the antennae of a newly isolated lepidopteran $G_{4}$ protein alpha subunit cDNA. Eur. J. Biochem. 269, 2133-2142.

Jin, X., Ha, T. S., and Smith, D. P. (2008). SNMP is a signaling component required for pheromone sensitivity in Drosophila. Proc. Natl. Acad. Sci. U.S.A. 105, 10996.

Johnson, B. R., Vligt, R., Merrill, C. L., and Atema, J. (1991). Across-fiber patterns may contain a sensory code for stimulus intensity. Brain Res. Bull. 26, 327-331.

Junek, S., Kludt, E., Wolf, R., and Schild, D. (2010). Olfactory coding with patterns of response latencies. Neuron 67, 872-884.

Justus, K. A., Carde, R. T., and French, A. S. (2005). Dynamic properties of antennal responses to pheromone in two moth species. J. Neurophysiol. 93, 2233-2239. 
Kain, P., Chandrashekaran, S., Rodrigues, V., and Hasan, G. (2008). Drosophila mutants in phospholipid signaling have reduced olfactory responses as adults and larvae. J. Neurogenet. 23, 303-312.

Kaissling, K.-E. (1987). "Stimulus transduction," in $R$. H. Wright Lectures on Insect Olfaction, ed. K. Colbow (Burnaby, BC: Simon Fraser University Press), 1-190.

Kaissling, K.-E. (2009). Olfactory perireceptor and receptor events in moths: a kinetic model revised.J. Comp. Physiol. A Neuroethol. Sens. Neural Behav. Physiol. 195, 895-922.

Kaissling, K.-E., and Boekhoff, I. (1993). "Transduction and intracellular messengers in pheromone receptor cells of the moth Antheraea polyphemus," in Sensory Systems of Arthropods, eds K. Wiese, F. G. Gribakin, A. V. Popov, and G. Renninger (Berlin: Birkhäuser), 489-502.

Kaissling, K.-E., Hildebrand, J. G., and Tumlinson, J. H. (1989). Pheromone receptor cells in the male moth Manduca sexta. Arch. Insect Biochem. Physiol. 10, 273-279.

Kaissling, K.-E., and Priesner, E. (1970). Smell threshold of the silkmoth. Naturwissenschaften 57, 23-28.

Kaissling, K.-E., and Thorson, J. (1980). "Insect olfactory sensilla: structural chemical and electrical aspects of the functional organization," in Receptors for Neurotransmitters, Hormones, and Pheromones in Insects, eds D. B. Satelle, L. M. Hall, and J. G. Hildebrand (Amsterdam: Elsevier/ North-Holland Biomedical Press), 261-282.

Kalidas, S., and Smith, D. P. (2002). Novel genomic cDNA hybrids produce effective RNA interference in adult Drosophila. Neuron 33, 177-184.

Kaupp, U. B. (2010). Olfactory signaling in vertebrates and insects: differences and commonalities. Nat. Rev. Neurosci. 11, 188-200.

Keil, T. (1989). Fine structure of the pheromone-sensitive sensilla on the antenna of the hawkmoth, Manduca sexta. Tissue Cell 21, 139-151.

Keil, T. A. (1993). Dynamics of "immotile" olfactory cilia in the silkmoth Antheraea. Tissue Cell 25, 573-587.

Keil, T. A. (1999). "Morphology and development of the peripheral olfactory organs," in Insect olfaction, ed. B.S. Hansson (Berlin: Springer), 6-47.

Keil, T. A., and Steinbrecht, R. A. (1984). "Mechanosensitive and olfactory sensilla of insects," in Insect Ultrastructure, Vol.2, eds R. C. King and H. Akai (New York: Plenum Press), 435-475.

Kennedy, J. S., Ludlov, A. R., and Sanders, D. J. (1981). Guidance of flying male moths by wind-born sex pheromone. Physiol. Entomol. 6, 395-412.

Klein, U., and Keil, T. A. (1984). Dendritic membrane from insect olfactory hairs: isolation method and electron microscopic observations. Cell. Mol. Neurobiol. 4, 385-396.

Knüsel, P., Carlsson, M. A., Hansson, B. S., Pearce, T. C., and Verschure, P. R. M. J. (2007). Time and space are complementary encoding dimensions in the moth antennal lobe. Network $18,35-62$.

Koehl, M.A.R. (2006). The fluid mechanics of arthropod sniffing in turbulent odor plumes. Chem. Senses 31, 93-105.

Krannich, S. (2008). Electrophysiological and Pharmacological Characterization of Ion Channels Involved in Moth Olfactory Transduction Cascades. Dissertation, University of Marburg, 1-114.

Krannich, S., and Stengl, M. (2008).Cyclic nucleotide-activated currents in cultured olfactory receptor neurons of the hawkmoth Manduca sexta. J. Neurophysiol. 100, 2866-2877.

Krieger,J.,Gondesen, I., Forstner,M., Gohl, T., Dewer, Y. M., and Breer, H. (2009). HR11 and HR13 receptor-expressing neurons are housed together in pheromone-responsive sensilla trichodea of male Heliothis virescens. Chem. Senses 34, 469-477.

Krieger,J., Grosse-Wilde, E., Gohl, T., and Breer, H. (2005). Candidate pheromone receptors of the silkmoth Bombyx mori. Eur. J. Neurosci. 21, 2167-2176.

Krieger, J., Grosse-Wilde, E., Gohl, T., Dewer Y.M.E., Raming, K., and Breer, H. (2004). Genes encoding candidate pheromone receptors in a moth (Heliothis virescens). Proc. Natl. Acad. Sci. U.S.A. 101, 11645-11850.

Krieger, J., Klink, O., Mohl, C., Raming, K., and Breer, H. (2003). A candidate olfactory receptor subtype highly conserved across different insect orders. $J$. Comp. Physiol. A 189, 519-526.

Krieger, J., Raming, K., Dewer, Y. M. E., Bette S., Conzelmann, S., and Breer, H. (2002). A divergent gene family encoding candidate olfactory receptors of the moth Heliothis virescens. Eur. J. Neurosci. 16, 619-628.

Krishnan, B., Dryer, S. E., and Hardin, P.E. (1999). Circadian rhythms in olfactory responses of Drosophila melanogaster. Nature 400, 375-378.

Krishnan, P., Chatterjee, A., Tanoue, S., and Hardin, P. E. (2008). Spike amplitude of single-unit responses in antennal sensillae is controlled by the Drosophila circadian clock. Curr. Biol. $18,803-807$.

Larsson, M. C., Domingos, A. L., Jones, W. D., Chiappe, M. E., Amrein, H., and Vosshall, L. B. (2004). Or83b encodes a broadly expressed odorant receptor essential for Drosophila olfaction. Neuron 43, 703-714.

Laue, M., Maida, R., and Redkozubov, A. (1997). G-protein activation, identification and immunolocalization in pheromone-sensitive sensilla trichodea of moths. Cell Tissue Res. 288 149-158.

Laue, M., and Steinbrecht, R. A. (1997). Topochemistry of moth olfactory sensilla.Int. J. Insect Morphol. Embryol. 26, 217-228.

Laughlin, J. D., Ha, T. S., Jones, D. N. M., and Smith, D. P. (2008). Activation of pheromone-sensitive neurons is mediated by conformational activation of pheromone-binding protein. Cell 133 , 1255-1265.

Laurent, G. (2002). Olfactory network dynamics and the coding of multidimensional signals. Nat. Rev. Neurosci. 3, 884-895.

Leal, W. S., Chen, A. M., Ishida, Y., Chiang, V. P., Erickson, M. L., Morgan, T. I., and Tsuruda,J.M. (2005). Kinetics and molecular properties of pheromone binding and release. Proc. Natl. Acad. Sci. U.S.A. 102, 5386-5391.

Lee, J. K., and Strausfeld, N. J. (1990). Structure, distribution, and number of surface sensilla and their receptor cells on the antennal flagellum of the male sphinx moth Manduca sexta. J. Neurocytol. 19, 519-538.

Lehman, H. K. (1990). Circadian control of Manduca sexta flight. Abstr. Soc. Neurosci. 16, 1334.

Lei, H., Riffell, J. A., Gage, S. L., and Hildebrand, J. G. (2009). Contrast enhancement of stimulus intermittency in a primary olfactory network and its behavioral significance. J. Biol. $8,1-15$.

Linn, C. E. Jr., and Roelofs, W. L. (1986). Modulatory effects of octopamine and serotonin on male sensitivity and periodicity of response to sex pheromone in the cabbage looper moth, Trichoplusia ni. Arch. Insect. Biochem. Physiol. 3, 161-171.

Lucas, P., and Pézier, A. (2006). DAG, calcium and chloride: partners involved in insect olfactory transduction. Chem. Senses 31, E81.

Lundin, C., Käll, L., Kreher, S. A., Kapp, K., Sonnhammer, S. L., Carson, J. R., Heijne, G., and Nilsson, I. (2007). Membrane topology of the Drosophila OR83b odorant receptor. FEBS Lett. 581, 5601-5604.

Maida, R., Redkozubov, A., and Ziegelberger, G. (2000). Identification of PLC beta and PKC in pheromone receptor neurons of Antheraea polyphemus. Neuroreport 11, 1773-1776.

Malpel, S., Merlin, C., François, M. C., and Jacquin-Joly, E. (2008). Molecular identification and characterization of two new Lepidoptera chemoreceptors belonging to the Drosophila melanogaster OR83b family. Insect. Mol. Biol. 17, 587-596.

Merlin, C., François, M. C., Queguiner, I., Maibèche-Coisné, M., and JacquinJoly, E. (2006). Evidence for a putative antennal clock in Mamestra brassicae: molecular cloning and characterization of two clock genes - period and cryptochrome - in antennae. Insect. Mol. Biol. 15, 137-145.

Merlin, C., Lucas, P., Rochat, D., François, M. C., Maibèche-Coisne, M., and Jacquin-Joly, E. (2007). An antennal circadian clock and circadian rhythms in peripheral pheromone reception in the moth Spodoptera littoralis. J. Biol. Rhythms 22, 502-514.

Milner, P. (1974). A model for visual shape recognition. Psychol. Rev. 81, 521-535.

Minor, A. V., and Kaissling, K.-E. (2003). Cell responses to single pheromone molecules may reflect the activation kinetics of olfactory receptor molecules. J. Comp. Physiol. A 189, 221-230.

Miura, N., Atsumi, S., Tabunoki, H., and Sato, R. (2005). Expression and localization of three $G$ protein subunits, Go, Gq, and Gs, in adult antennae of the silkmoth (Bombyx mori). J. Comp. Neurol. 485, 143-152.

Mohl, C., Breer, H., and Krieger, J. (2002). Species-specific pheromonal compounds induce distinct conformational changes of pheromone binding protein subtypes from Antheraea polyphemus. Invert. Neurosci. 4, 165-174.

Morton, D. (2004). Invertebrates yield a plethora of atypical guanylyl cyclases. Mol. Neurobiol. 29, 97-116.

Morton, D., and Nighorn, A. (2003). MsGC-II, a receptor guanylyl cyclase isolated from the CNS of Manduca sexta that is inhibited by calcium. $J$. Neurochem. 84, 363-372.

Murlis, J., and Jones, C. (1981). Fine-scale structure of odour plumes in relation to insect orientation to distant pheromone and other attractant sources. Physiol. Entomol. 6, 71-86.

Nadasdy, Z. (2010). Binding by asynchrony: the neuronal phase code Front. Neurosci. 4:51. doi: 10.3389/ fnins.2010.00051

Nakagawa, T., Sakurai, T., Nishioka, T., and Touhara, K. (2005). Insect sex pheromone signals mediated by specific combinations of olfactory receptors. Science 307, 1638-1642.

Nakagawa, T., and Vosshall, L. (2009). Controversy and consensus: noncanonical signaling mechanisms in the insect olfactory system. Curr. Opin. Neurobiol. 19, 284-292. 
Nighorn, A., Simpson, P. J., and Morton, D. B. (2001). The novel guanylyl cyclase Ms GC-I is strongly expressed in higher order neuropils in the brain of Manduca sexta. J. Exp. Biol. 204, 305-314.

Patch, H., Velarde, R. A., Walden, K. K. O., and Robertson, H. M. (2009). A candidate pheromone receptor and two odorant receptors of the hawkmoth Manduca sexta. Chem. Senses 34, 305-316.

Pelosi, P., Zhou, J. J., Ban, L. P., and Calvello, M. (2006). Soluble proteins in insect chemical communication. Cell. Mol. Life Sci. 63, 1658-1676.

Pézier, A., Acquistapace, A., Renou, M., Rospars, J.-P., and Lucas, P. (2007). $\mathrm{Ca}^{2+}$ stabilizes the membrane potential of moth olfactory receptor neurons at rest and is essential for their fast repolarization. Chem. Senses 32, 305-317.

Pézier, A., Grauso, M., Acquistapace, A., Monsempes, C., Rospars, J.-P., and Lucas, P. (2010). Calcium activates a chloride conductance likely involved in olfactory receptor neuron repolarization in the moth Spodoptera littoralis. J. Neurosci. 30, 6323-6333.

Pophof, B. (2000). Octopamine modulates the sensitivity of silkmoth pheromone receptor neurons. J. Comp. Physiol. A 186, 307-313.

Pophof, B. (2002). Octopamine enhances moth olfactory responses to pheromones, but not those to general odorants. J. Comp. Physiol. A 188, 659-662.

Pophof, B. (2004). Pheromone-binding proteins contribute to the activation of olfactory receptor neurons in the silkmoths Antheraea polyphemus and Bombyx mori. Chem. Senses 29, 117-125.

Pophof, B., and van der Goes van Naters, W. (2002). Activation and inhibition of the transduction process in silkmoth olfactory receptor neurons. Chem. Senses 27, 435-443.

Raman, B., Tang, J. J., and Stopfer, M. (2010). Temporally diverse firing patterns in olfactory receptor neurons underlie spatiotemporal neural codes for odors. J. Neurosci. 30, 1994-2006.

Raming, K., Krieger, J., and Breer, H. (1989). Molecular cloning of an insect pheromone-binding protein. FEBS Lett. 256, 215-218.

Rogers, M. E., Steinbrecht, R.A., and Vogt, R. G. (2001a). Expression of SNMP-1 in olfactory neurons and sensilla of male and female antennae of the silkmoth Antheraea polyphemus. Cell Tissue Res. 303, 433-446.

Rogers, M. E., Krieger, J., and Vogt, R. G. (2001b). Antennal SNMPs (sensory neuron membrane proteins) of Lepidoptera define a unique family of invertebrate CD36-like proteins. J. Neurobiol. 49, 47-61.

Rogers, M. E., Sun, M., Lerner, M. R., and Vogt, R. G. (1997). SNMP-1, a novel membrane protein of olfactory neurons of the silk moth Antheraea polyphemus with homology to the CD36 family of membrane proteins. J. Biol. Chem. 272, 14792-14799.

Rützeler, M., and Zwiebel, I. J. (2005). Molecular biology of insect olfaction: recent progress and conceptual models. J. Comp. Physiol. A 191, 777-790.

Saifullah, A. S., and Page, T. L. (2009). Circadian regulation of olfactory receptor neurons in the cockroach antenna. J. Biol. Rhythms 24, 144-152.

Sakurai, T., Nakagawa, T., Mitsuno, H., Mori, H., Endo, Y., Tanoue, S., Yasukochi, Y., Touhara, K., and Nishioka, T. (2004). Identification and functional characterization of a sex pheromone receptor in the silkmoth Bombyx mori. Eur. J. Neurosci. 21, 2167-2176.

Sanes, J. R., and Hildebrand, J. G. (1976). Origin and morphogenesis of sensory neurons in an insect antenna. Dev. Biol. 51, 300-319.

Sato, K., Pellegrino, M., Nakagawa, T., Nakagawa, T., Vosshall, L. B., and Touhara, K. (2008). Insect olfactory receptors are heteromeric ligandgated ion channels. Nature 452, 1002-1006.

Schleicher, S., Boekhoff, I., Konietzko, U., and Breer, H. (1994). Pheromoneinduced phosphorylation of antennal proteins from insects. J. Comp. Physiol. B 164, 76-80.

Schmidt, C. J., Garen-Fazio, S., Chow, Y. K., and Neer,E. J. (1998). Neuronal expression of a newly identified Drosophila melanogaster $\mathrm{G}$ protein alpha o subunit. Cell Regul. 1, 125-134.

Schneider, N.-L., and Stengl, M. (2005). Pigment-dispersing factor and GABA synchronize insect circadian clock cells. J. Neurosci. 25, 5138-5147.

Schneider, N.-L., and Stengl, M. (2006). Gap junctions between accessory medulla neurons appear to synchronize circadian clock cells. J. Neurophysiol. 95, 1996-2002.

Schneider, N.-L., and Stengl, M. (2007). Long term recordings of the isolated circadian pacemaker center of the cockroach Leucophaea maderae reveals circadian and ultradian rhythms. $J$. Comp. Physiol. A 193, 35-42.

Schuckel, J., Siwicki, K. K., and Stengl, M. (2007). Putative circadian pacemaker cells in the antenna of the hawkmoth Manduca sexta. Cell Tissue Res. 330, 271-278.

Silbering, A. F., and Benton, R. (2010). Ionotropic and metabotropic mechanisms in chemoreception: "chance or design"? EMBO Rep. 11, 173-179.

Silverstein, R. L., and Febbraio, M. (2009). CD36, a scavenger receptor involved in immunity, metabolism, angiogenesis, and behavior. Sci. Signal. 2, re3.

Simpson, P. J., Nighorn, A., and Morton, D. B. (1999). Identification of a novel guanylyl cyclase that is related to receptor guanylyl cyclases, but lacks extracellular and transmembrane domains. J. Biol. Chem. 274, 4440-4446.

Singer, W.., and Gray, C. (1995). Visual feature integration and the temporal correlation hypothesis. Annu. Rev. Neurosci. 18, 555-586.

Smart, R., Kiely, A., Beale, M., Vargas, E., Carraher, C., Kraliecek, A. V., Christie, D. L., Chen, C., Newcomb, R. D., and Warr, C. G. (2008). Drosophila odorant receptors are novel seven transmembrane domain proteins that can signal independently of heterotrimeric $\mathrm{G}$ proteins. Insect Biochem. Mol. Biol. 38, 770-780.

Steinbrecht, R. A., Laue, M., and Ziegelberger, G. (1995). Immunocytochemistry of odorantbinding protein and general binding protein in olfactory sensilla of the silk moths Antheraea and Bombyx. Cell Tissue Res. 282, 203-217.

Stengl, M. (1990). Development of an In Vitro Model System to Study Primary Sensory Transduction Mechanisms. Dissertation, ARL, University of Arizona, 1-177.

Stengl,M.(1993). Intracellular-messengermediated cation channels in cultured olfactory receptor neurons. J. Exp. Biol. 178, 125-147.

Stengl, M. (1994). Inositol-trisphosphatedependent calcium currents precede cation currents in insect olfactory receptor neurons. J. Comp. Physiol. A 174, 187-194.

Stengl, M., and Hildebrand, J. G. (1990). Insect olfactory neurons in vitro: morphological and immunocytochemical characterization of male-specific antennal receptor cells from developing antennae of male Manduca sexta. J. Neurosci. 10, 837-847.

Stengl, M., and Zintl, R. (1996). NADPHdiaphorase staining in the antenna of the moth Manduca sexta. J. Exp. Biol. 199, 1063-1072.

Stengl, M., Homberg, U., and Hildebrand, J. G. (1990). Acetylcholinesterase activity in antennal receptor neurons of the sphinx moth Manduca sexta. Cell Tissue Res. 262, 245-252.

Stengl, M., Ziegelberger, G., Boekhoff, I., and Krieger, J. (1999). "Perireceptor events and transduction mechanisms in insect olfaction," in Insect Olfaction, ed. B. S. Hansson (Berlin: Springer), 49-66.
Stengl, M., Zintl, R., de Vente, J., and Nighorn, A. (2001). Localization of cGMP-immunoreactivity and of soluble guanylyl cyclase in antennal sensilla of the hawkmoth Manduca sexta. Cell Tissue Res. 304, 409-421.

Stengl, M., Zufall, F., Hatt, H., and Hildebrand, J. G. (1992). Olfactory receptor neurons from antennae of developing male Manduca sexta respond to components of the species-specific sex pheromone in vitro. J. Neurosci. 12, 2523-2531.

Talluri, S., Bhatt, A., and Smith, D. P. (1995). Identification of a Drosophila G protein alpha subunit ( $\mathrm{dG}_{\mathrm{q}}$ alpha-3) expressed in chemosensory cells and central neurons. Proc. Natl. Acad. Sci. U.S.A. 92, 11475-11479.

Tanoue, S., Krishnan, P., Chatterjee, A., and Hardin, P. E. (2008). G proteincoupled receptor kinase 2 is required for rhythmic olfactory responses in Drosophila. Curr. Biol. 18, 787-794.

Tanoue, S., Krishnan, T., Krishnan, B., Dryer, S. E., and Hardin, P. E. (2004). Circadian clocks in antennal neurons are necessary and sufficient for olfaction rhythms in Drosophila. Curr. Biol. 14, 638-649.

Thurm, U., and Küppers, J. (1980). "Epithelial physiology of insect sensilla," in Insect Biology in the Future, eds M. Locke and D. S. Smith (New York: Academic Press), 735-763.

Tripathy, S., Peters, O. J., Staudacher, E. M., Kalwar, F. R., Hatfield, M. N., and Daly, K. C. (2010). Odors pulsed at wing beat frequencies are tracked by primary olfactory networks and enhance odor detection. Front. Cell. Neurosci. 16:1. doi: 10.3389/ neuro.03.001.2010

Tumlinson, J. H., Brennan, M. M., Doolittle, R. E., Mitchell, E. R., Brabham, A., Mazomemos. B. E., Baumhover, A. H., and Jackson, D. M. (1989). Identification of a pheromone blend attractive to Manduca sexta (L.) males in a wind tunnel. Arch. Insect Biochem. Physiol. 10, 255-271.

Vickers, N. J. (2000). Mechanisms of animal navigation in odor plumes. Biol. Bull. 198, 203-212.

Vickers, N. J., and Baker, T.C. (1992). Male Heliothis virescens maintain upwind flight in response to experimentally pulsed filaments of their sex pheromone (Lepidoptera: Noctuidae). J. Insect Behav. 5, 669-687.

Vogt, R. G., Miller, N. E., Litvack, R., Fandino, R. A., Sparks, J., Staples, J., Friedman, R., and Dickens, J.C. (2009). The insect SNMP gene family. Insect Biochem. Mol. Biol. 39, 448-456.

Vogt, R. G., and Riddiford, L. M. (1981). Pheromone binding and inactivation by moth antennae. Nature 293, 161-163. 
Vogt, R. G., and Riddiford, L. M. (1986). "Pheromone reception: a kinetic equilibrium," Mechanisms in Insect Olfaction, eds T. L. Payne, M. C. Birch and E. J. Kennedy (Oxford: Clarendon), 201-208.

von Frisch, K. (1921). Über den Sitz des Geruchssinnes bei Insekten. Zool. Jahrb. Abt. Allgem. Zool. Physiol. Tiere 38, 449-516.

Von Nickisch-Rosenegk, E., Krieger, J., Kubick, S., Laage, R., Strobel, J., Stotmann, H., and Breer, H. (1996). Cloning of biogenic amine receptors from moths (Bombyx mori and Heliothis virescens). Insect Biochem. Mol. Biol. 26, 817-827.

Wegener, J. W., Hanke, W., and Breer, H. (1997). Second messenger-controlled membrane conductance in locust (Locusta migratoria) olfactory receptor neurons. J. Insect. Physiol. 43, 595-605.

Wicher, D, Schäfer, R., Bauernfeind, R., Stensmyr, M. C., Heller, R., Heinemann, S. H., and Hansson, B. S. (2008). Drosophila odorant receptors are both ligand-gated and cyclicnucleotide-activated cation channels. Nature 452, 1007-1011.

Xu, P. X., Atkinson, R., Jones, D. N. M., and Smith, D. P. (2005). Drosophila OBP LUSH is required for activity of pheromone-sensitive neurons. Neuron 45, 193-200.

Ziegelberger, G. (1995). Redox-shift of the pheromone-binding protein in the silkmoth Antheraea polyphemus. Eur. J. Biochem. 232, 706-711.

Ziegelberger, G., Van den Berg, M. J., Kaissling, K.-E., Klumpp, S., and Schultz, J.E. (1990). Cyclic nucleotide levels and guanylate cyclase activity in pheromonesensitive antennae of the silkmoths Antheraea polyphemus and Bombyx mori. J. Neurosci. 10, 1217-1225.

Zufall, F., and Hatt, H. (1991). Dual activation of a sex pheromone-dependent ion channel from insect olfactory dendrites by protein kinase $\mathrm{C}$ activators and cyclic GMP. Proc. Natl. Acad. Sci. U.S.A. 88, 8520-8524.

Zufall, F., Stengl, M., Franke, C., Hildebrand, J.G., and Hatt, H. (1991a). Ionic currents of cultured olfactory receptor neurons from antennae of male Manduca sexta. J. Neurosci. 11 956-965.

Zufall, F., Franke, C., and Hatt, H. (1991b). A calcium-activated nonspecific cation channelfromolfactory receptorneurons of the silkmoth Antheraea polyphemus. J. Exp. Biol. 161, 455-468.
Conflict of Interest Statement: The author declares that the research was conducted in the absence of any commercial or financial relationships that could be construed as a potential conflict of interest.

Received: 31 May 2010; paper pending published: 07 September 2010; accepted 16 December 2010; published online: 31 December 2010

Citation: Stengl M (2010) Pheromone transduction in moths. Front. Cell. Neurosci. 4:133. doi: 10.3389/fncel.2010.00133 Copyright (c) 2010 Stengl. This is an openaccess article subject to an exclusive license agreement between the authors and the Frontiers Research Foundation, which permits unrestricted use, distribution, and reproduction in any medium, provided the original authors and source are credited. 